\title{
Facile synthesis of 2D ultrathin and ultrahigh specific surface hierarchical porous carbon nanosheets for advanced energy storage
}

Yuechao Yao ${ }^{\mathrm{a}}$, Zunqin Xiao ${ }^{\mathrm{a}}$, Peng Liu ${ }^{\mathrm{a}}$, Shengjiao Zhang ${ }^{\mathrm{a}}$,Yuan Niu ${ }^{\mathrm{a}}$, Hongliang $\mathrm{Wu}^{\mathrm{a}}$, Shiyu Liu ${ }^{\mathrm{a}}$, Wenxuan $\mathrm{Tu}^{\mathrm{a}}$, Qi Luo ${ }^{\mathrm{a}}$, Muhammad Aurang Zeb Gul Sial ${ }^{\mathrm{a}}$, Shaozhong Zeng ${ }^{\mathrm{a}}$, Qi zhang ${ }^{\mathrm{a}, \mathrm{b}}$, Jizhao Zou ${ }^{\mathrm{a} *}$, Xierong Zeng ${ }^{\mathrm{a},}$,Wenjing Zhang ${ }^{\mathrm{c} *}$

${ }^{a}$ Shenzhen Key Laboratory of Special Functional Materials \& Shenzhen Engineering Laboratory for Advance Technology of ceramics, College of Materials Science and Engineering, Shenzhen University, Shenzhen, 518060. P.R. China

${ }^{\mathrm{b}}$ School of Aerospace, Transport and Manufacturing, Cranfield University, Cranfield, Bedfordshire MK43 0AL, UK

${ }^{\mathrm{c}}$ Department of Environmental Engineering, Technical University of Denmark, Miljøvej 113, DK-2800 ,Kongens Lyngby, Denmark

* Corresponding author.

E-mail address: zoujizhao@szu.edu.cn (J.Z.Zou) and wenz@dtu.dk (Wenjing (Angela) Zhang)

\begin{abstract}
Two dimensional (2D) porous carbon nanosheets (CNS) have attracted tremendous research interests in energy storage and conversion, such as supercapacitors (SCs) and lithium-sulfur batteries, because of their unique micromorphology, chemical stability and high specific surface area (SSA). Rational design and facile scalable synthesis of
\end{abstract}


CNS with high SSA, low cost and ultrathin nanosheet structure is highly desired but hitherto remains a big challenge. Here, we report a novel synthesis method of 2D hierarchical porous CNS with ultrahigh SSA $\left(2687 \mathrm{~m}^{2} \mathrm{~g}^{-1}\right)$ and ultrathin structure by directly pyrolysing and activating a unique and abundant biomass sheet. The electrochemical characterisations show that the prepared CNS-4-1 materials as electrodes creates a good energy-storage capability, with the energy density being 91 $\mathrm{Wh} \mathrm{kg}^{-1}$ for symmetric SCs in ionic liquids, which is the highest in the reported biomass-derived CNS materials for SCs applications so far. Besides, the CNS-5-1 also exhibits a high initial capacity of $1078 \mathrm{mAh} \mathrm{g}^{-1}$ at $0.1 \mathrm{C}$ when it acted as a sulfur hosting material for lithium-sulfur batteries. More importantly, it also shows a 586 $\mathrm{mAh} \mathrm{g}^{-1}$ reversible capacity and an approaching $100 \%$ coulombic efficiency after 500 cycles at a high rate of $1 \mathrm{C}$. These superior electrochemical properties of the CNS are mainly attributed to their unique 2D ultrathin nanosheet structure, large SSA, and reasonable hierarchical porous structure. This work not only provides a new strategy to fabricate the ultrathin CNS in large scale and low cost but also enlarges CNS materials potential applications in energy storage.

Keywords: carbon nanosheets, ultrahigh SSA, high-performance, lithium-sulfur batteries, supercapacitors

\section{Introduction}

The rapid development of advanced technology in the $21^{\text {st }}$ century has accelerated the requirement of energy, but traditional energy storage devices cannot keep pace 
with high-consumption devices. To tackle this dilemma, developing energy storage and conversion devices with high-efficiency and capacity, such as supercapacitors (SCs), rechargeable batteries and fuel cells, is an essential task of scientific research. A key point for coining high-performance energy storage devices is to design and structure the electrodes using active materials with excellent physicochemical properties. Porous carbon materials, compared with other electrode materials, have the merits of low price, good conductivity, tuneable pore structure and easy fabrication and thus have acquired great attention in energy storage fields. Moreover, as compared to traditional porous carbon materials with irregular or zero-dimensional structure, CNS materials with their unique 2D structures offers many advantages when being applied as electrode materials in the nergy storage devices[1, 2];1. Faster ion transportation channel and higher conductivity due to the $2 \mathrm{D}$ structure[3]; 2 . higher SSA and abundant electrochemically active sites for electrochemical reactions[4]; 3. More durable cycling performance due to the high internal pore volume for mitigating abrupt changes in volume during charging/discharging processes.[5] Therefore, developing a facile scalable method to synthesis CNS materials is highly desired for advancing energy storage technology.

Jiang et al. reported a spontaneous gas-foaming method to prepare CNS by pyrolysing a mixture of citric acid and $\mathrm{NH}_{4} \mathrm{Cl}$. Under the pyrolysis temperature of $1000{ }^{\circ} \mathrm{C}$ and the precursor mass ratio of $1: 1$, the resulting materials have a $2 \mathrm{D}$ sheet structure with high SSA $\left(1793 \mathrm{~m}^{2} \mathrm{~g}^{-1}\right)$, and exhibit excellent performance in oxygen reduction reaction [6]. Moreover, Yao et al. synthesised a hierarchical porous CNS by 
one-step pyrolysing and activating a nitrogen-containing thermoset polymer[7]. The obtained CNS with a $2406 \mathrm{~m}^{2} \mathrm{~g}^{-1} \mathrm{SSA}$ can obtain up to $139 \mathrm{Wh} \mathrm{kg}^{-1}$ energy density at a power density of $500 \mathrm{~W} \mathrm{~kg}^{-1}$ in supercapacitors. Zhao et al. [8] reported a bottom-up synthesis of the ultrathin $\mathrm{Zn}(\mathrm{bim})(\mathrm{OAc}) \mathrm{MOF}$ nanosheets and their derived N-doped porous CNS for energy storage. The CNS shows a capacitance of $278 \mathrm{~F} \mathrm{~g}^{-1}$ at a current density of $10 \mathrm{~A} \mathrm{~g}^{-1}$. However, these conventional CNS synthesis methods often involve more toxic chemicals and are both time-consuming and energy-intensive. Thus, developing a highly effective, sustainable and large-scale method to obtain ideal CNS materials is essential.

Lately, biomass-derived CNS materials[9-11] attract great attention of researchers because biomass is abundant, easy-to-access and sustainable. Our earlier paper[12] reported a porous CNS with a high SSA of $1234 \mathrm{~m}^{2} \mathrm{~g}^{-1}$ obtained by a simple carbonisation procedure with carefully selected carbon precursors. When these porous CNS were used as electrodes in SCs, a capacitance of $213 \mathrm{~F} \mathrm{~g}^{-1}$ can be acquired at a current density of $0.1 \mathrm{~A} \mathrm{~g}^{-1}$. Wang et al. reported a facile and versatile salt-sealing technique to prepare functional porous carbon sheets (PCSs) from fresh clover stems[13], and the PCSs exhibit a high gravimetric specific capacitance of $436 \mathrm{~F} \mathrm{~g}^{-1}$ at $1 \mathrm{~A} \mathrm{~g}^{-1}$. Despite of the recent progress made in preparing the biomass-derived CNS materials, a novel and scalable synthesis method to prepare high-performance biomass-derived CNS materials with ultrahigh SSA and ultrathin structure remain unexplored. 


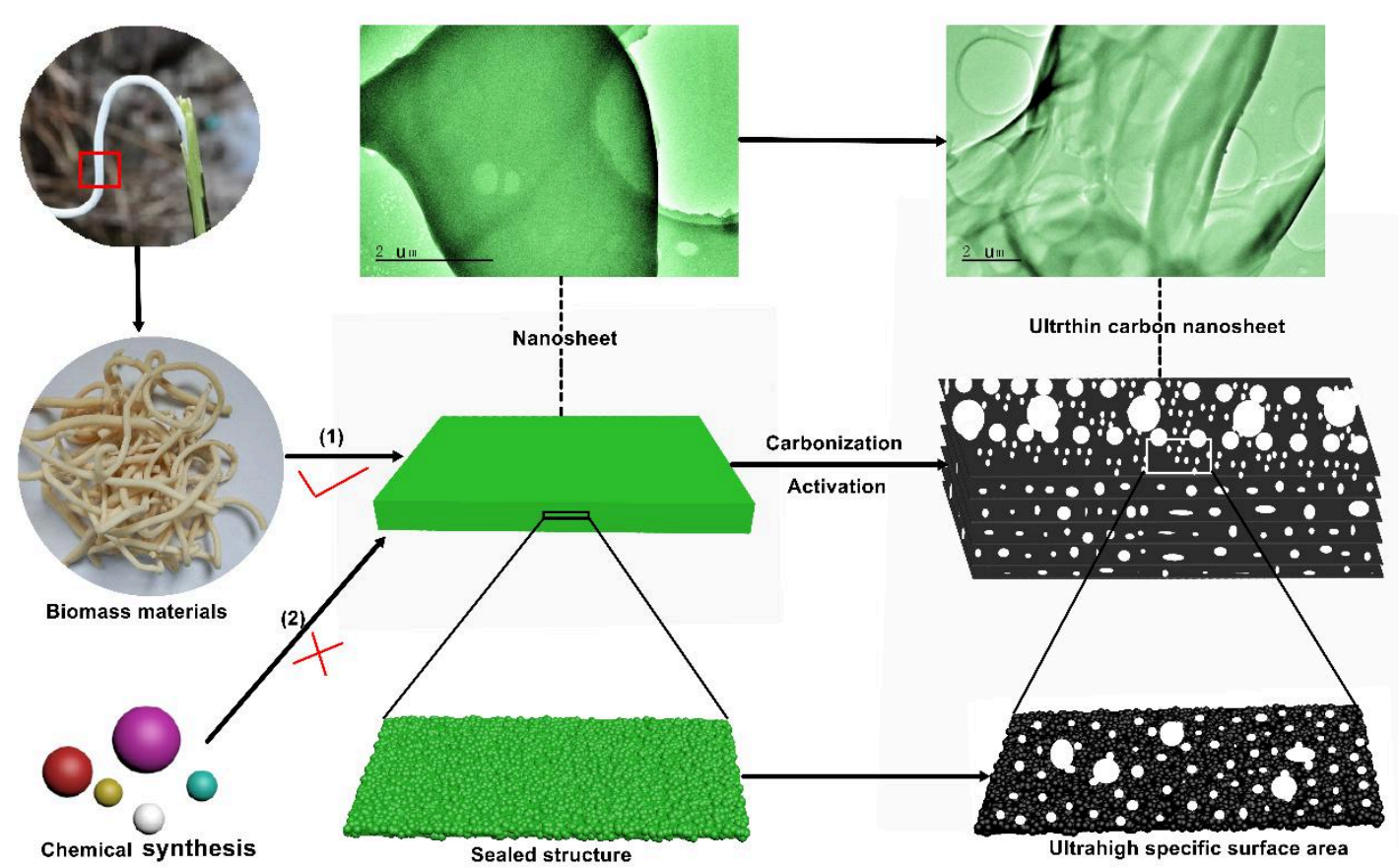

Figure 1 The schematic of synthesis of carbon nanosheets.

Herein, we propose a facile method to develop a class of well-defined CNS materials that possess a 2D sheet structure, ultrahigh SSA $\left(2687 \mathrm{~m}^{2} \mathrm{~g}^{-1}\right)$ as well as the ultrathin (4 nm) thickness. As shown in Figure 1, CNS materilas are fabricated by simple carbonization of biomass precursor (Stachyurus Chinensis Franch, more information can be seen in supplementary materials Figure S1) followed by activation process instead of choosing hazardous complicated chemical methods. This is realized by careful selection of carbon precursors and pyrolysis procedures. Given CNS merits, we further systemically investigated their applications in energy storages. For example, the resulting CNS materials as the electrode materials in SCs exhibit a high specific capacitance of $300 \mathrm{~F} \mathrm{~g}^{-1}$ at $0.25 \mathrm{~A} \mathrm{~g}^{-1}$. When assembled into a symmetric SC device with ionic liquid as electrolyte, the CNS electrode provides a higher gravimetric energy density $\left(91 \mathrm{Wh} \mathrm{kg}^{-1}\right)$ than commercial active carbon materials. 
Morevoer, the obtained CNS materials can act as a sulfur host material in lithium-sulfur batteries. The electrochemical performance of the optimal sample of CNS-5-1 shows excellent cycling stability (only $0.048 \%$ attenuation of each cycle after 500 cycles at $1 \mathrm{C}$ ), which are superior, in energy storage field, to most of the recently reported biomass-derived CNS materials.

\section{Experimental}

\subsection{The synthesis of CNS}

The precursors of biomass (Stachyurus Chinensis Franch) were acquired from Xiangxi Minority Autonomous Region, Hunan Province, China. All biomass precursors were used as received and dried before use. The dried sample was heated from room temperature to $800{ }^{\circ} \mathrm{C}$ with the heating rate of $10{ }^{\circ} \mathrm{C} / \mathrm{min}$, and then hold at $800{ }^{\circ} \mathrm{C}$ for $1 \mathrm{~h}$ under Ar atmosphere. The obtained CNS was chemically activated using $\mathrm{KOH}$. The $\mathrm{KOH}$ and CNS were grounded in an agate mortar in a mass ratio (2:1, $3: 1,4: 1$ or $5: 1$ ), and then the mixture was carbonized at $800{ }^{\circ} \mathrm{C}$ for $1 \mathrm{~h}$ under argon flow, followed by cooling down to room temperature. In order to melt $\mathrm{KOH}$, when the activated temperature rises to $450{ }^{\circ} \mathrm{C}$, and it remains for $0.5 \mathrm{~h}$. Then, the obtained samples were thoroughly washed with $10 \mathrm{wt} \% \mathrm{HCl}$ in distilled water. Finally, the 4 CNS samples with varied mass ratios of $\mathrm{KOH}$ and CNS (CNS-2-1, CNS-3-1, CNS-4-1 and CNS-5-1) were dried in an oven at $70{ }^{\circ} \mathrm{C}$ for $12 \mathrm{~h}$.

\subsection{Preparation of $\mathrm{CNS}-\mathrm{X}-1(\mathrm{X}=2,3,4,5) / \lambda \mathrm{S}$ composites}

Different amounts of sulfur (Aldrich, with a purity of $>99.995 \%$ ) and CNS-X-1(X=2, $3,4,5)$ were thoroughly grounded in a quartz mortar with adding $\mathrm{CS}_{2}$ twice until it 
turns into a uniform black mixture. The mixture was put into a glass container and heated to $155^{\circ} \mathrm{C}$ in an oven, and remained for $12 \mathrm{~h}$ to ensure sulfur thoroughly infiltrating into CNS-X-1, leading to the formation of CNS-X-1/ $\lambda \mathrm{S}$ composites $(\lambda$ represent the percentage of sulfur in composites).

\subsection{Characterization}

X-ray diffraction (XRD) patterns were recorded on a Bruker D8 advance powder X-ray diffractometer using $\mathrm{Cu} \mathrm{K} \alpha$ radiation. A Hitachi SU-70 FESEM instrument was used for field emission scanning electron microscopy (FESEM) images and transmission electron microscopy (TEM) was conducted via a JEOL 2011 TEM facility. The analysis of Laser Raman spectroscopy was performed on a RenishawinVia Spectrometer. X-ray photoelectron spectroscopy (XPS) was used on a ULVAC-PHI 1800 spectrometer. The SSAs were characterised by the gas sorption technique using a Micromeritics ASAP 2020 based on the Brunauere-Emmette-Teller (BET) method. The electrochemical properties were characterized on an electrochemistry workstation (CHI660E), and the cycle performance of coin SCs and lithium-sulfur batteries was studied on a NEWARE (Shenzhen, China) instruments. Bruker Dimension ICON was used to investigate the images of Atomic Force Microscope (AFM).

\subsection{The fabrication of electrode and electrochemical measurements}

\subsubsection{Supercapacitors (SCs):}

Electrochemical tests were carried out under a standard three-electrode system equipped with $\mathrm{Pt}$ counter electrode, $\mathrm{Hg} / \mathrm{HgO}$ reference electrode and the working 
electrode. The working electrode was prepared as follows: The acquired CNS-X-1 materials were grounded with acetylene black and PTFE suspension in an agate mortar until forming a sheet. The mass ratio for active material: acetylene black: PTFE was 80:10:10. The prepared electrode of CNS-X-1 was made into a sheet of 1 $\mathrm{cm}^{2}$, and then the sheet was pressed between two nickel foams with $10 \mathrm{MPa}$.

For the two-electrode configuration in $6 \mathrm{~mol} \cdot \mathrm{L}^{-1} \mathrm{KOH}$ aqueous electrolyte, the prepared electrodes were assembled with a cellulose film as the separator.

Coin-cell SCs were further constructed by assembling two pieces of the electrode with a cellulose film as a separator and an ionic liquid $\mathrm{EMIIMBF}_{4}$ as the electrolyte in a glove box filling with argon. The mass of the active materials was $8 \mathrm{mg}$. The testing frequency of electrochemical impedance spectroscopy (EIS) is from $100 \mathrm{kHz}$ to 0.01 Hz. To better reflect the electrochemical performance of CNS in SCs, the capacitance contribution of Nickel foam acting as a collector were investigated, and its related data are acting as a blank sample adding in Supplementary materials (Figure S2 and Table S1).

In the three-electrode configuration, the $\mathrm{C} 3 \mathrm{E}$ of CNS was calculated using Eq (1):

$$
\mathrm{C} 3 \mathrm{E}=\frac{I \Delta \mathrm{t}}{m \Delta \mathrm{V}}
$$

In this formula $\mathrm{C}_{3 \mathrm{E}}\left(\mathrm{F} \mathrm{g}^{-1}\right), \mathrm{m}(\mathrm{g}), \mathrm{I}(\mathrm{A}), \Delta \mathrm{t}(\mathrm{s})$, and $\Delta \mathrm{V}(\mathrm{V})$ mean specific capacitance, mass of the working electrode, discharge current, discharge time, and discharge voltage, respectively. 
In the two-electrode configuration, the $\mathrm{C}_{2 \mathrm{E}}$ of $\mathrm{CNS}$ was calculated using Equation

(2): $\mathrm{C} 2 \mathrm{E}=\frac{4 I \Delta \mathrm{t}}{M \Delta \mathrm{v}}$

$M$ is the mass of the two electrode materials in a device. The energy density (E) and power density (P) were calculated using Equation (3) and (4):

$\mathrm{E}=\frac{1}{28.8} \mathrm{C} V^{2}$

$\mathrm{P}=\frac{3600 E}{\Delta T}$

where $\mathrm{C}\left(\mathrm{F} \mathrm{g}^{-1}\right)$ represents the specific capacitance of the SCs measured from the Equation (2), Potential (V) the potential change within the discharge time $\Delta \mathrm{T}(\mathrm{s}), \mathrm{E}$ $\left(\mathrm{Wh} \mathrm{kg}^{-1}\right)$ the energy density, and $\mathrm{P}\left(\mathrm{W} \mathrm{kg}^{-1}\right)$ the power density.

\subsubsection{Lithium-sulfur batteries}

For the CNS-X-1/ $\lambda \mathrm{S}(\mathrm{X}=2,3,4,5 ; \lambda=60)$ and CNS-5-1/80S cathodes, $80 \mathrm{wt} \%$ of CNS-X-1/ $\lambda, 10 \mathrm{wt} \%$ of acetylene black and $10 \mathrm{wt} \%$ of LA133 binder were dispersed in distilled water and ground for $1 \mathrm{~h}$. The obtained slurry was cast onto an Al-foil current collector by a doctor-blade method with a height of 200 um. The cathode loading amount was about $1.2 \mathrm{mg} \mathrm{cm}^{-2}$, and the amount of sulfur in the cathode was approximately $0.5 \mathrm{mg} \mathrm{cm}^{-2}$. The high loading cathodes were fabricated as above processes, excepte for the changing the proportion of $\mathrm{C} / \mathrm{S}$ composite, acetylene black and LA133 binder (7:1:2). All cathodes were dried at $60^{\circ} \mathrm{C}$ for $24 \mathrm{~h}$ under vacuum. The dried electrodes were cut by a disc cutter (MTI, 15mm diameter).

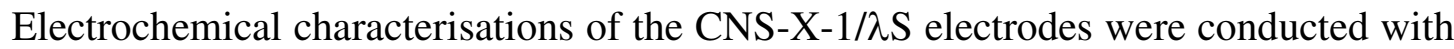
CR2016 coin-type cells assembled in a glove box under Ar atmosphere using lithium 
foil as the counter electrode. The electrolyte for $\mathrm{Li}-\mathrm{S}$ is $1.0 \mathrm{M}$ lithium bis(trifluoromethanesulfonyl)imide (LiTFSI) salt that was dissolved in a hybrid solution of 1,3-dioxolane and dimethoxymethane (1:1 in volume) with $1 \mathrm{wt} \% \mathrm{LiNO}_{3}$ as an additive. The cycle performance was studied under the voltage window of 1.7-2.8 V for Li-S batteries at $25^{\circ} \mathrm{C}$. Cyclic voltammetry (CV) curves were tested at a scanning rate of $0.2 \mathrm{mV} \mathrm{s}^{-1}$ with the potential range of $1.7-2.8 \mathrm{~V}$ for Li-S batteries.

\section{Results and discussion}

\subsection{Characterization of CNS}

Stachyurus Chinensis Franch (SCF) is a kind of common plant and widely spread in the most of the regions of China, and it is well-known because of its medical value from its inner structure (Scheme 1a-b). Because of the unique structure of this biomass material with extremely low density and microstructure of sheet, we investigated its derived materials performances. As revealed by the SEM result in Figure 2a, the inner substance from SCF has a particular well-defined sheet structure with large scale. To the best of our knowledge, these merits have never been reported before[2, 13-16]. This regular large scale sheet morphology of SCF inner substance laid the foundation to prepare the CNS materials. The clearer sheet structure can be seen in Figure $2 \mathrm{~b}$ after the precursor was carbonized to synthesis CNS materials. Figure 2c is the high-resolution SEM image of CNS, and some pores can be clearly obversved. This shows that direct carbonization of the precursor can form some CNS with porous structure. When the CNS experienced the activation process, a pleated-shaped CNS-5-1 with more pores can be obtained, as shown in Figure $2 \mathrm{~d}$. 
Figure 2e illustrates the ultrathin nanosheet morphology of CNS-5-1. Figure $2 \mathrm{f}$ is the high-resolution SEM of CNS-5-1 and shows a highly porous structure of CNS-5-1.
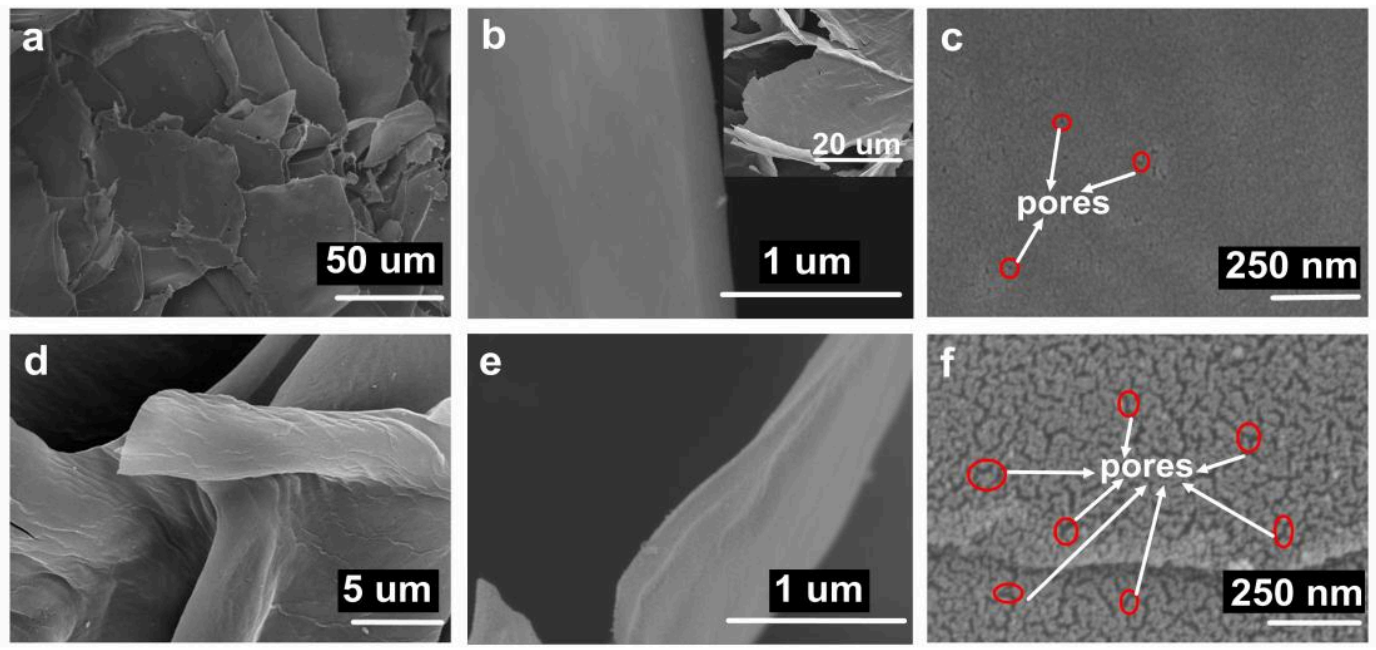

Figure 2. The SEM images of precursor (a), CNS (b-c) and CNS-5-1(d-f).

The TEM results (Figure 3a-f) further illustrate the sheet morphology and the porous characteristic. Figure 3a-b highlights the exceptionally thick sheet structure of CNS without activation, although it consists of a few pores in the higher resolution of CNS (Figure 3c). As shown in Figure 3d, when CNS was activated by $\mathrm{KOH}$, it is composed of highly porous and ultrathin CNS, which is comparable with the super-thin carbon film coated on the TEM copper grid. Clearer sheet morphology is exhibited in Figure 3e, corresponding to the pleated-shaped structure (Figure 2d). The high-resolution TEM result of CNS-5-1 further illustrates its highly porous structure. The similar structure also can be obtained as shown in supplementary materials Figure S3. The AFM result of CNS-5-1(Figure 3g-h) illustrates that the obtained ultrathin CNS can decrease to thickness of $4 \mathrm{~nm}$. 

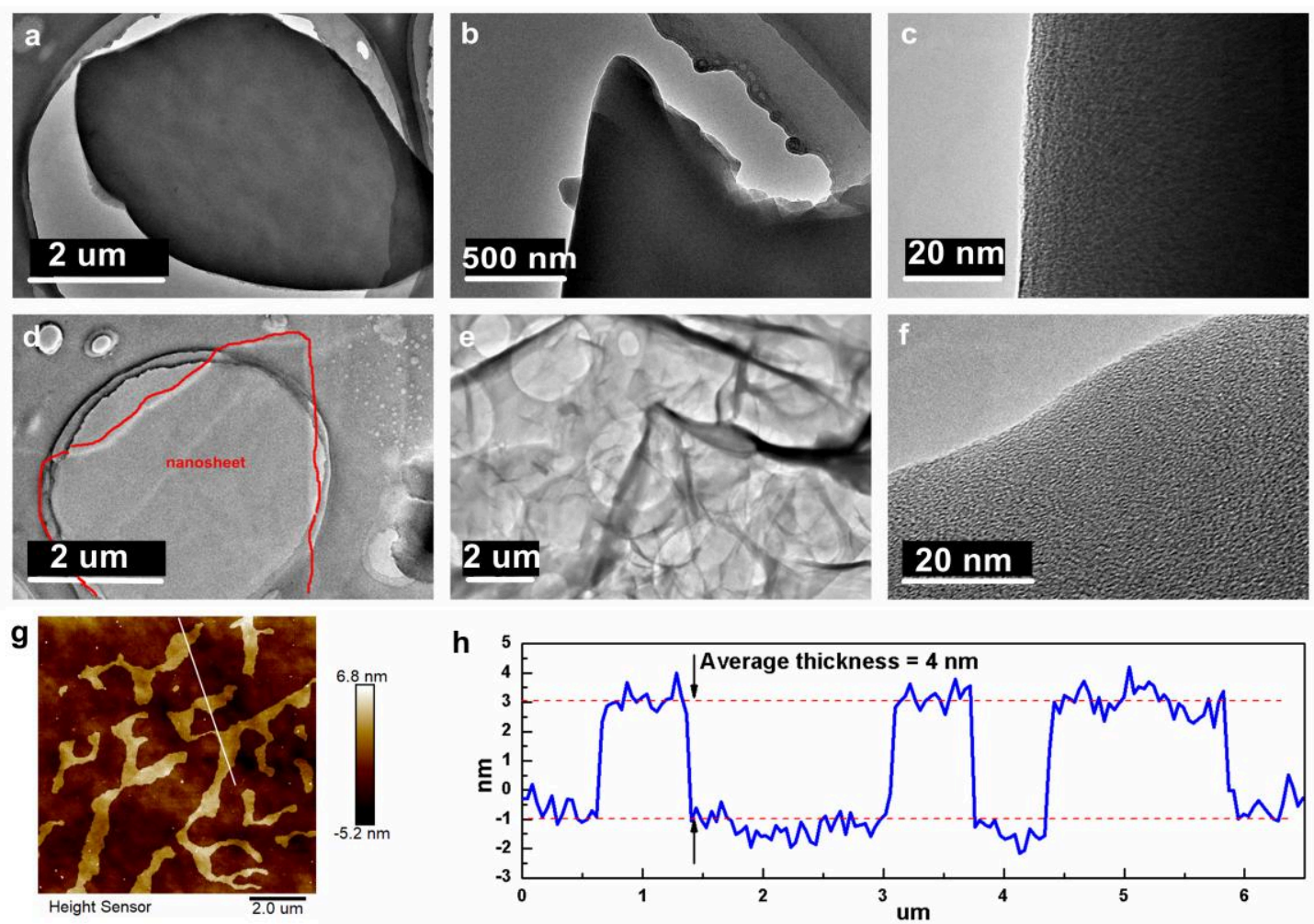

Figure 3.The TEM images of CNS (a-c) and CNS-5-1 (d-f). g) AFM image of CNS-5-1 on a Si substrate. h) The specific thickness of CNS-5-1 corresponding to the white line in Figure 3g.

The structures of the CNS and CNS-X-1(X=2, 3, 4, 5) were investigated by XRD, Raman spectroscopy and BET analysis. Figure 4a shows the XRD results for these carbon samples. The broad diffraction peak at approximately the $2 \theta$ angles of $24^{\circ}$ and $44^{\circ}$, corresponding to the (002) and (101) planes of the amorphous carbon derived directly from SCF (i.e., CNS). After dealing with the activation of $\mathrm{KOH}$, the strength of diffraction peak became broader, weaker, and even disappeared when the activator increased to $500 \%$ (CNS-5-1), which could attribute to the increase of nanopores in the sample that introduces structural disorder[7, 8]. The Raman spectra of CNS materials are shown in Figure 4b, and their value of ID/IG was calculated (supplementary materials Table S2). The ID means the intensity of disorder degree of graphitic lattice or sp3-rich phase, and the IG represents the intensity of graphite 
domains and sp2-bonded forms of carbon $[1,6]$. It is obvious that the ID/IG value for CNS-X-1(X=2, 3, 4, 5) was increased with increasing the amount of $\mathrm{KOH}$ (from 0.848 increase to 0.947$)$. It can attribute to the fact that the activation effect will increase as the $\mathrm{KOH}$ ratio increase, which means that the speed of $\mathrm{KOH}$ captures carbon will exacerbate and further produces more disordered pores and increase the intensity of disordered degree. Meanwhile, the same activation temperature maintains the uniformity of the IG values (IG tends to be more affected by carbonised temperature). As a result, the ID/IG value of CNS-X-1(X=2, 3, 4, 5) generally shown a raising tendency with the increase of the proportion of $\mathrm{KOH}$. The SSA and porous structure of the prepared samples were further characterized by $\mathrm{N}_{2}$ ad-desorption isotherm. Figure $4 c$ shows $\mathrm{N}_{2}$ ad-desorption isotherm of CNS and CNS-X-1(X=2, 3, 4, 5). It is clearly shown that the SSAs of CNS materials increase with the increasing ratio of $\mathrm{KOH}$ to $\mathrm{CNS}$ during the activation process. This could be attributed to the pore formation due to the reaction between $\mathrm{KOH}$ and the carbon in CNS materials[17, 18]. The SSA of CNS and CNS-X-1 (X=2, 3, 4, 5) (supplementary materials Table S2) are 495, 1816, 1994, 2619 and $2687 \mathrm{~m}^{2} \mathrm{~g}^{-1}$ based on the BET method. The samples of CNS-4-1 and CNS-5-1 show a typical type I/IV isotherms, which confirm the existence of numerous micropores and mesopores among these materials[19, 20]. Figure $4 \mathrm{~d}$ shows the corresponding pore size distribution curves of CNS and CNS-X-1 $(\mathrm{X}=2,3,4,5)$, and it further fitted the results of co-existence between micropores and mesopores. The micropores dramatically enhance the capability of CNS-X-1 $(\mathrm{X}=2,3,4,5)$ to strengthen electronic ad-desorption in SCs and confine 
polysulphides from dissolving in lithium-sulfur batteries[21-23], while mesopores provide more channel to accelerate ion transportation[24].
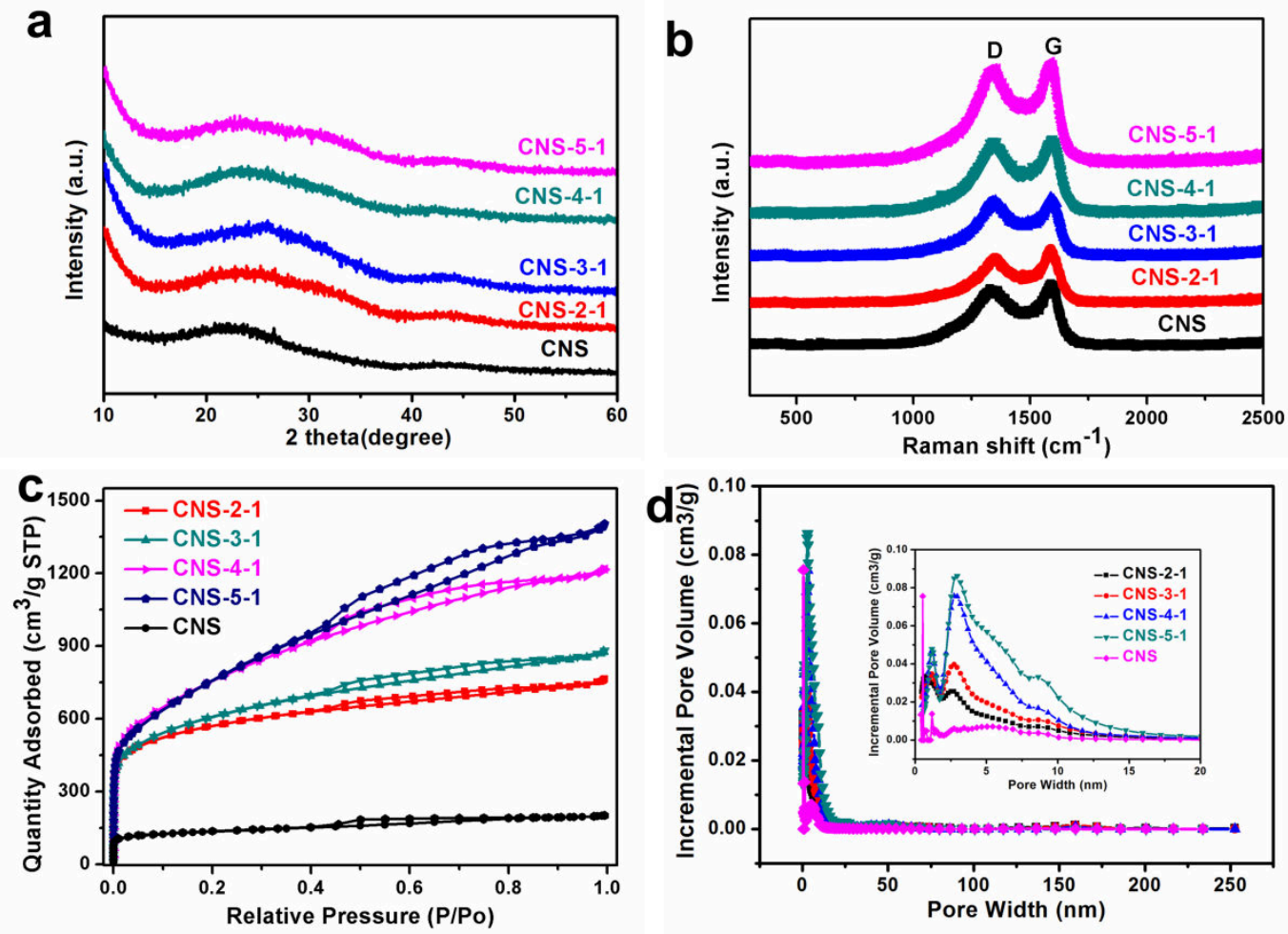

Figure 4. a) The $X$-Raw diffraction, b) Raman spectra, c) $\mathrm{N}_{2}$ de-adsorption isotherm and d) specific pore distribution curves of CNS and CNS-X -1 $(X=2,3,4,5)$.

\subsection{Electrochemical properties in SCs}

Given the merits of porous CNS materials with ultrahigh SSA and ultrathin sheet structure, we anticipated that the CNS materials would be promising electrode materials in SCs. To evaluate the performance of CNS electrodes in SCs, we systemically investigated the capacitive behaviour of $\mathrm{CNS}-\mathrm{X}-1(\mathrm{X}=2,3,4,5)$ using three-electrode configuration (Figure 5). The GCD curves of CNS-X-1 $(X=2,3,4,5)$ are shown in Figure 5a, and all electrodes show symmetric triangle curves indicating an ideal electrical-double-layer (EDL) capacitive behaviour[25]; Moreover, the CNS-4-1 possesses longest discharge time, which means that CNS-4-1 can obtain 
maximum capacitance $\left(241.9 \mathrm{~A} \mathrm{~g}^{-1}\right)$ at the current density of $1 \mathrm{~A} \mathrm{~g}^{-1}$. The $\mathrm{CV}$ curves (Figure 5b) for all samples show a nearly rectangular shape, which further demonstrates the EDL capacitive capabilities for prepared electrode materials. CNS-4-1 with the largest integral area of CV obtained the optimal capacitance in all samples. GCD curves of CNS-X-1 (X=2, 3, 4, 5) electrodes at different current densities suggest good symmetry, and the corresponding CV curves at different scan rates also indicate good reversibility (Supplementary materials Figure S4). These results illustrate that CNS materials have a faster ion diffusion rate. Figure $5 \mathrm{c}$ shows the specific capacitances of various current densities for CNS-X-1 $(X=2,3,4,5)$ electrodes. It is obvious that CNS-4-1 exhibits the best performance in all samples; More specifically, the CNS-4-1 can obtain up to $300 \mathrm{~F} \mathrm{~g}^{-1}$ capacitance at the current density of $0.1 \mathrm{~A} \mathrm{~g} \mathrm{~g}^{-1}$ compared to that of CNS-2-1 (197 F g $\left.{ }^{-1}\right), \mathrm{CNS}-3-1\left(237 \mathrm{~F} \mathrm{~g}^{-1}\right)$ and CNS-5-1 (238.5 $\left.\mathrm{F} \mathrm{g}^{-1}\right)$. When the testing current density increases to $40 \mathrm{~A} \mathrm{~g}^{-1}, \mathrm{a}$ capacitance of $185 \mathrm{~A} \mathrm{~g}^{-1}$ for CNS-4-1 electrode was obtained. Although CNS-5-1 has the largest SSA $\left(2687 \mathrm{~m}^{2} \mathrm{~g}^{-1}\right)$ and pore volume $\left(2.15 \mathrm{~cm}^{3} \mathrm{~g}^{-1}\right)$, its micropores as the main contributor to the EDL capacitance are drastically reduced (from $317 \mathrm{~m}^{2} \mathrm{~g}^{-1}$ of CNS-4-1 decrease to $85 \mathrm{~m}^{2} \mathrm{~g}^{-1}$, Supplementary materials Table S2) due to excessive activation, resulting in a rapid decrease in capacitance. As shown in Figure 5c, the rate performance of CNS-X-1 indicates a downward tendency with the increasing of the activator content. This could be attributed to the presence of a large number of pores that affect the conductivity of themselves, to some extent. Figure $5 \mathrm{~d}$ indicates the Nyquist plots for all samples. With the amount of $\mathrm{KOH}$ increasing, the impedance 
and diffusion resistance of electrodes increased, resulting in further coincides with our conjecture. However, due to the high initial capacitance, CNS-4-1 still indicates the best performance compared to CNS-2-1 and CNS-3-1. Overall, the high performance of CNS-4-1 could be attributed to its unique nanosheet morphology, hierarchical porous structure as well as the ultrahigh SSA.
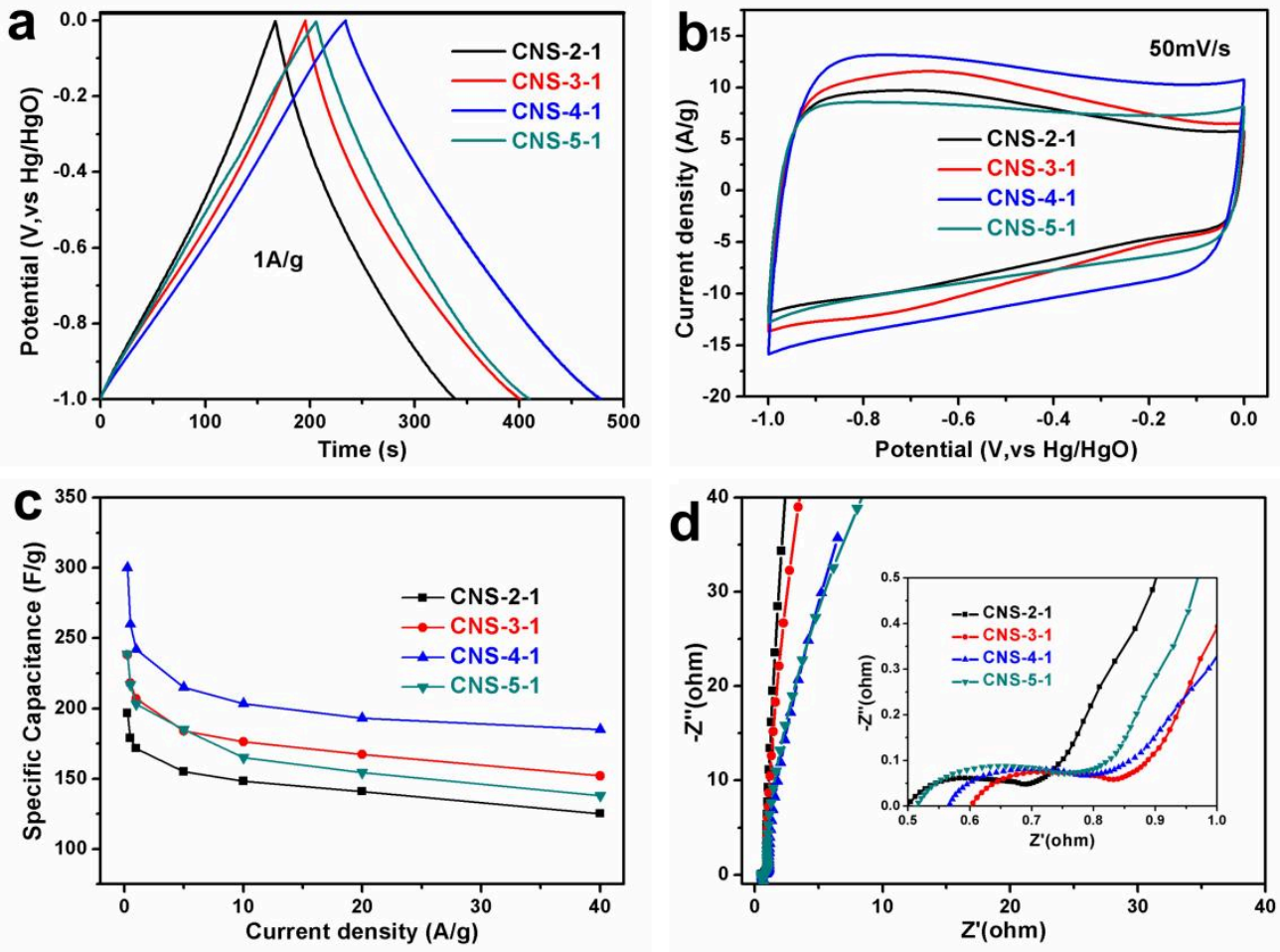

Figure 5. Electrochemical characterization of the CNS-X-1 $(X=2,3,4,5)$ as electrode materials with three-electrode configuration at $6 \mathrm{M} \mathrm{KOH}$ electrolyte. a) GCD curves for different CNS-X-1 $(\mathrm{X}=2,3,4,5)$ measured at $1 \mathrm{~A} \mathrm{~g}^{-1}$. b) $\mathrm{CV}$ curves for the CNS-X-1 $(\mathrm{X}=2,3,4,5)$ measured at 50 $\mathrm{mVs}^{-1}$. c) The specific capacitance of the electrodes as various current densities. d) The Nyquist plots of all samples.

Next, we further investigated capacitive performance of CNS-4-1 electrodes by assembling symmetric SCs devices in an aqueous and ionic electrolyte. The schematic illustration of the constructed device is shown in Figure 6a, where two electrodes are separated by a separator. The whole device was filled with electrolyte with $6 \mathrm{M} \mathrm{KOH}$ 
or $\mathrm{EMIMBF}_{4}$. Figure 6b shows the CV curves of CNS-4-1 electrodes in SCs devices (6 $\mathrm{M} \mathrm{KOH}$ aqueous electrolyte). $\mathrm{CV}$ curves at different scan rates show a rectangular shape, indicating an ideal capacitive behaviour and remarkable rate performance, which could be attributed to the hierarchical porous and 2D ultrathin sheet structure ensuring fast diffusion for electrolyte ions at high charge/discharge rates for the SCs devices.

Furthermore, the GCD profiles (Figure 6c) of the CNS-4-1 electrode also show highly triangle shape and slight IR drop, illustrating excellent electrochemical reversibility. Electrochemical performance of the CNS-4-1 in a two-electrode configuration using $\mathrm{EMIMBF}_{4}$ as an electrolyte was further studied. Figure $6 \mathrm{~d}$ shows the CV curves of CNS-4-1 electrodes at $50 \mathrm{mV} \mathrm{s}^{-1}$ when the scan voltage window continuously changed. It shows the CNS-4-1 SCs can operate at $4.0 \mathrm{~V}$ without apparent increasing of anodic current. Not utterly similar to the aqueous system of SCs, the CV curves (Figure 6e) ranging from 5 to $200 \mathrm{mV} \mathrm{s}^{-1}$ cannot maintain a complete rectangular shape. Meanwhile, the corresponding GCD curves have a slight IR drop (Figure 6f), due to the lower ionic conductivity of $\mathrm{EMIMBF}_{4}$ electrolyte as compared to that of 6 $\mathrm{M} \mathrm{KOH}$ electrolyte. The Nyquist plots of CNS-4-1 in two electrolyte systems are further investigated (Supplementary materials Figure S5) the above result. Figure $6 \mathrm{~g}$ compared the specific capacitance performance in two electrolyte systems. It shows that in aqueous electrolyte, at the same current density, CNS-4-1 electrodes can acquire higher capacitance than in ionic electrolyte $\left(174 \mathrm{~F} \mathrm{~g}^{-1}\right.$ in aqueous electrolyte; $163 \mathrm{~F} \mathrm{~g}^{-1}$ in ionic liquids, at the current density of $0.25 \mathrm{~A} \mathrm{~g}^{-1}$ ). When current density 
increases to $2 \mathrm{~A} \mathrm{~g}^{-1}$, the capacitances of CNS-4-1 are $145 \mathrm{~F} \mathrm{~g}^{-1}(6 \mathrm{M} \mathrm{KOH})$ and $89 \mathrm{~F}$ $\mathrm{g}^{-1}\left(\mathrm{EMIMBF}_{4}\right)$. Given the merit of better ionic conductivity in the aqueous electrolyte, the CNS-4-1 electrodes sustain a better capacitance on a large current density in aqueous electrolyte.

The Ragone plots of CNS-4-1-based SCs with different electrolytes systems were calculated by Equation (3) and (4) and exhibited in Figure 6h. Compared to the aqueous system, a high working voltage of CNS-4-1 in ionic liquids endows the SCs devices with high energy densities. In particular, the energy density of CNS-4-1 SCs is $6.04 \mathrm{Wh} \mathrm{kg}^{-1}$ at a power density of $124 \mathrm{~W} \mathrm{~kg}^{-1}$, and retains $3.75 \mathrm{Wh} \mathrm{kg}^{-1}$ at $10 \mathrm{~kW}$ $\mathrm{kg}^{-1}$ at aqueous electrolyte. More importantly, the energy density of CNS-4-1 based on SCs is $91 \mathrm{Wh} \mathrm{kg}^{-1}$ at a power density of $200 \mathrm{~W} \mathrm{~kg}^{-1}$, and still retains $49 \mathrm{Wh} \mathrm{kg}^{-1}$ at $4.9 \mathrm{~kW} \mathrm{~kg}^{-1}$ in the ionic liquids. To our best knowledge, this performance is the best among all biomass-derived CNS related electrode materials reported in literatures[13-16, 26-29], also more clearly related data can be seen in Supplementary materials Table S3. Supplementary materials in Figure S6 show the cycling performance of CNS-4-1 in ionic liquids and $68.2 \%$ of initial capacitance can be retained after 10,000 cycles at $2 \mathrm{~A} \mathrm{~g}^{-1}$. Furthermore, the assembled SCs device using the CNS-4-1 as the electrodes lighted LED bulb and mini fan (internal image in Figure 6g) to illustrate its actual application in energy storage fields. The related video can be seen in Supplementary video. 

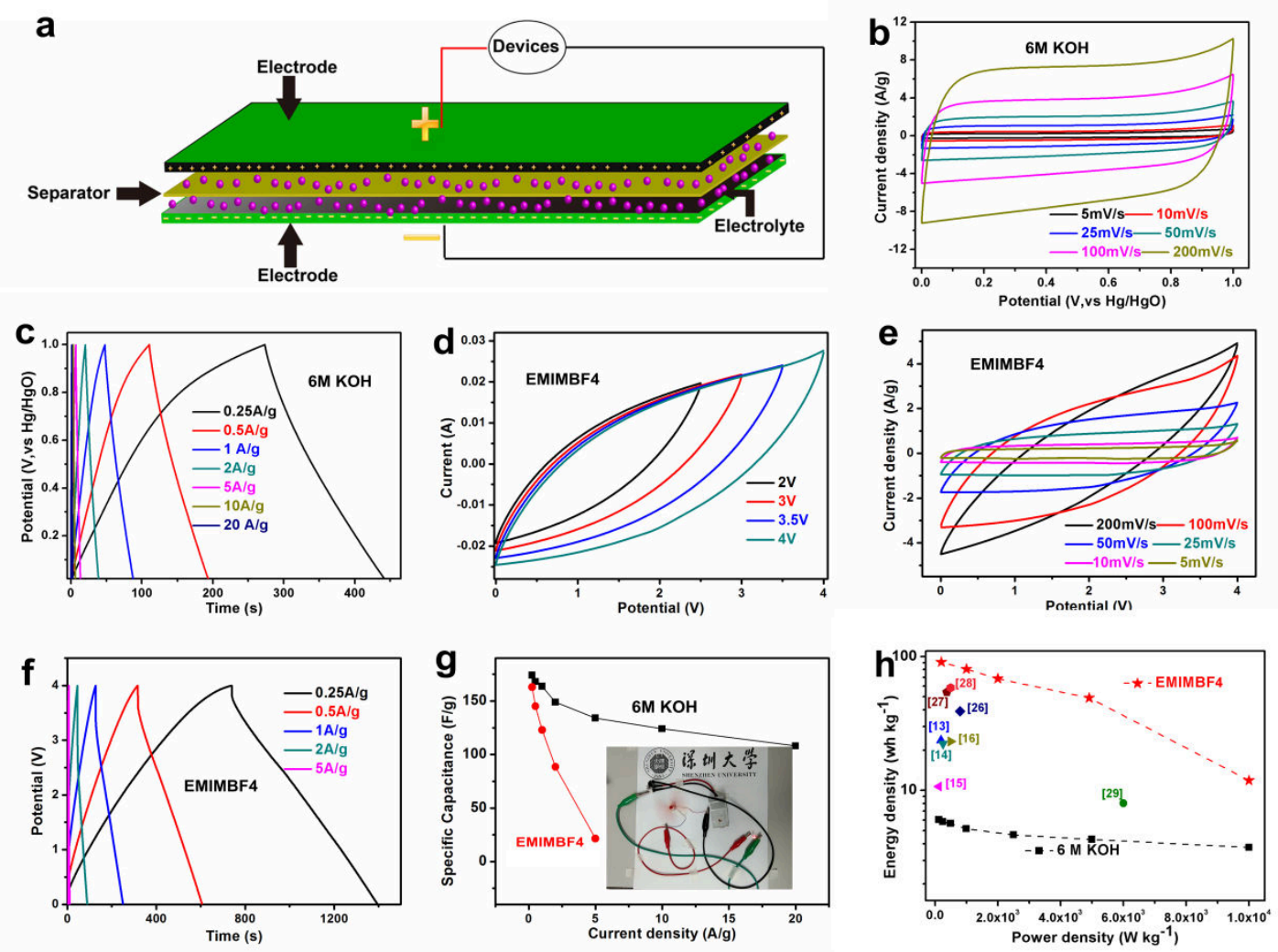

Figure 6. Electrochemical characterisation of assembling SCs devices based on the CNS-4-1 with $6 \mathrm{M} \mathrm{KOH}$ and $\mathrm{EMIMBF}_{4}$ electrolyte. a) Schematic illustration of the device configuration. b) $\mathrm{CV}$ curves for the CNS-4-1-based SCs device at different scant rates (6 M KOH). c) GCD curves for the CNS-4-1-based SCs device measured at different current densities (6 M KOH). d) CV curves for the CNS-4-1-based SCs device at different scan window $\left(\mathrm{EMIMBF}_{4}\right)$. e) CV curves for the CNS-4-1-based SCs device at different scant rates $\left(\mathrm{EMIMBF}_{4}\right)$. f) GCD curves for the CNS-4-1-based SCs devices measured at different current densities $\left(\mathrm{EMIMBF}_{4}\right)$. g) Specific capacitance as a function of the current density (inner digital images: Photograph demonstrates that CNS-4-1-based SCs can light up LED and mini fan). h) Ragone plot for the CNS-4-1-based SCs with different electrolytes and a comparison with literature data relating to CNS materials.

\subsection{Electrochemical properties in Lithium-sulfur batteries}

Lithium-sulfur batteries have a high theoretical capacity $\left(1675 \mathrm{~mA} \mathrm{~h} \mathrm{~g}^{-1}\right)$ and energy density (2600 $\mathrm{Wh} \mathrm{kg}^{-1}$ ), and sulfur as cathodic material is cheap and abundant in resource on earth. Therefore, owing to these merits, lithium-sulfur batteries attract a great attention[30, 31]. However, there are some problems with using sulfur in energy storage devices. Firstly, elemental sulfur can easily form soluble polysulfides 
resulting in the shuttle effect during the cycling process[32]; Moreover, the poor conductivity of sulfur is another problem limting its performance in energy storage applications[33]. To overcome these problems, we used the synthesised 2D CNS with ultrathin and ultrahigh SSA as sulfur host materials and systemically investigated their specific performance in lithium-sulfur batteries.
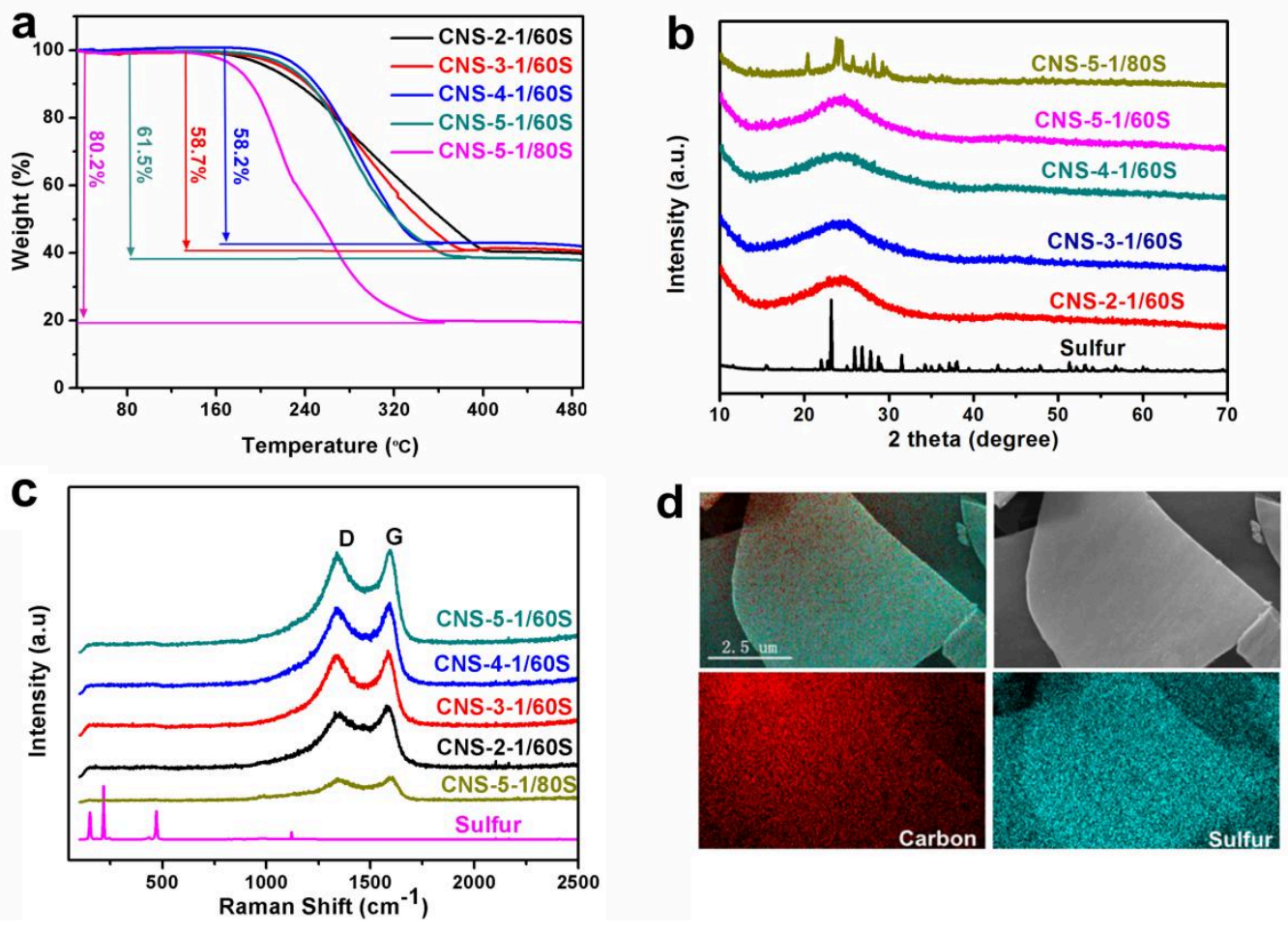

Figure 7.a) The TGA profiles forCNS-X-1/60S(X=2, 3, 4, 5) and CNS-5-1/80S. b) XRD patterns, c) Raman spectra for pristine sulfur, CNS-X-1/60S(X=2, 3, 4, 5) and CNS-5-1/80S. g) The elemental maps of CNS-5-1/60S.

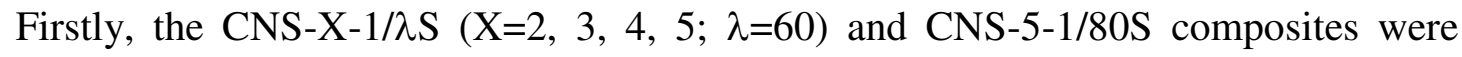
prepared by the melt-diffusion method, and thermogravimetric analysis (TGA) was conducted to evaluate the sulfur content in all samples. The TGA results (Figure 7a) show that $\mathrm{CNS}-\mathrm{X}-1 / \lambda \mathrm{S}(\mathrm{X}=2,3,4,5 ; \lambda=60)$ and $\mathrm{CNS}-5-1 / 80 \mathrm{~S}$ had a sulfur content of about 58.7, 58.7, 58.2, 61.5 and 81.2 wt $\%$ according to the weight loss between $150{ }^{\circ} \mathrm{C}$ and $350{ }^{\circ} \mathrm{C}$. Figure $7 \mathrm{~b}$ indicates the XRD patterns of the CNS-X-1/ $\lambda \mathrm{S}(\mathrm{X}=2,3$, 
$4,5 ; \lambda=60)$ and CNS-5-1/80S composites, and all the samples only show the amorphous graphite peak of CNS-X-1 (X=2, 3, 4, 5) except for CNS-5-1/80S composite, suggesting sulfur was successfully incorporated into the pores of prepared host materials. The pore volume of CNS-5-1/80S composite is limited and cannot store exorbitant sulfur, and further lead to the existence of the partly diffraction peaks

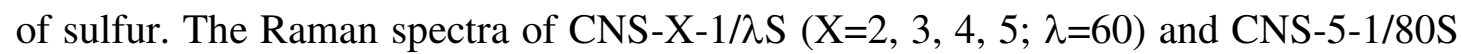
are further proven the observation from the XRD and get a complete correspondence. Moreover, with the infiltration of sulfur, the all samples values of $\mathrm{I}_{\mathrm{D}} / \mathrm{I}_{\mathrm{G}}$ are changed slightly (Supplementary material Table S2), which means that sulfur is effectively loaded in the pores of CNS materials. The corresponding element mapping of S and C is shown in Figure 7d, which was used to analyse the distribution of each element in the CNS-5-1/60S composite. It can be observed that all detected elements, including S and $\mathrm{C}$, are homogeneously distributed in the CNS-5-1/60S composite. All the other samples exhibit the same results as shown in Supplementary material Figure S7. 

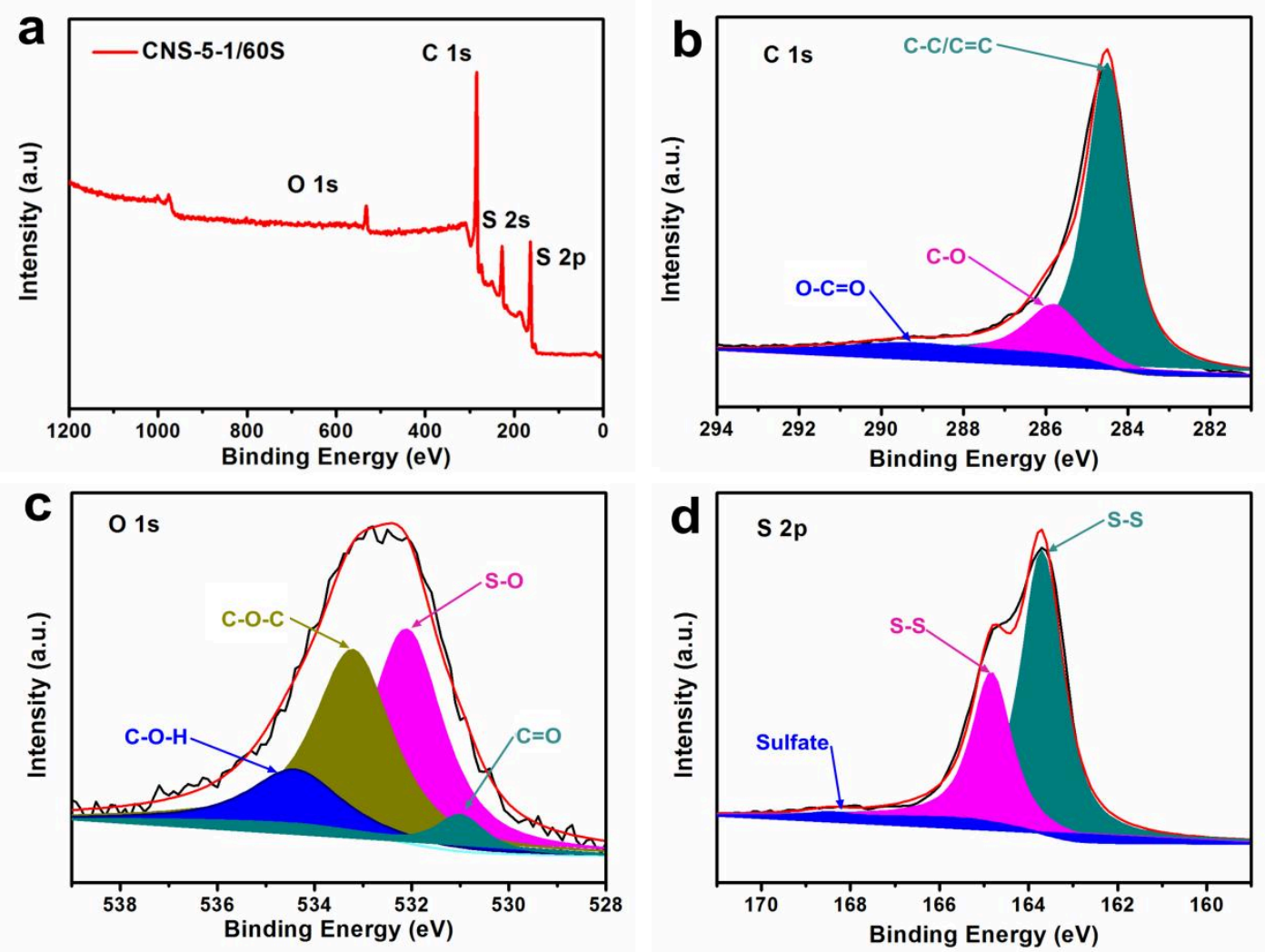

Figure 8. a) Overall XPS spectra of CNS-5-1/60S. b), c) and d) are matched XPS spectra of C 1s, $\mathrm{O} 1 \mathrm{~s}$ and $\mathrm{S} 2 \mathrm{p}$, respectively.

To better investigate the elemental chemical state of CNS-X-1/ $\lambda \mathrm{S}$, the XPS spectra of CNS-5-1/60S, as a representative, were performed. The survey XPS spectra of CNS-5-1/60S (Figure 8a) confirm that $\mathrm{C}, \mathrm{O}$ and $\mathrm{S}$ exist in the composite. The high-resolution C 1s spectra of CNS-5-1/60S in Figure $8 \mathrm{~b}$ can be fitted to the three peaks of $\mathrm{C}-\mathrm{C} / \mathrm{C}=\mathrm{C}(\sim 284.5 \mathrm{eV}), \mathrm{C}-\mathrm{O}(\sim 285.8 \mathrm{eV})$ and $\mathrm{O}-\mathrm{C}=\mathrm{O}(\sim 289.5 \mathrm{eV})[22,34]$. As shown in Figure 8c, the high-resolution O 1s spectra can be fitted to four peaks at 531.0, 532.2, 533.2 and $534.3 \mathrm{eV}$, which correspond to the $\mathrm{C}=\mathrm{O}, \mathrm{S}-\mathrm{O}, \mathrm{C}-\mathrm{O}-\mathrm{C}$ and C-O-H bonds, respectively $[35,36]$. These $\mathrm{C}-\mathrm{O}-\mathrm{C}$ and $\mathrm{C}=\mathrm{O}$ groups on the surface of CNS-5-1 are essential for anchoring polysufides and for limiting the grain growth of $\mathrm{Li}_{2} \mathrm{~S}, \mathrm{Li}_{2} \mathrm{~S}_{2}$ and sulfur$[37,38]$. Moreover, the $\mathrm{S} 2 \mathrm{p}$ of CNS-5-1/60S composite can be 
fitted into three peaks (Figure $8 d$ ). In particular, the $S 2 p_{3 / 2}$ and $S 2 p_{1 / 2}$ have an energy separation of $1.2 \mathrm{eV}$ and intensity ratio of $2: 1$, relating to the previous report for amorphous sulfur. The third peak at $168.1 \mathrm{eV}$ can be ascribed to the sulfate species formed upon oxidation of sulfur in the air[38].
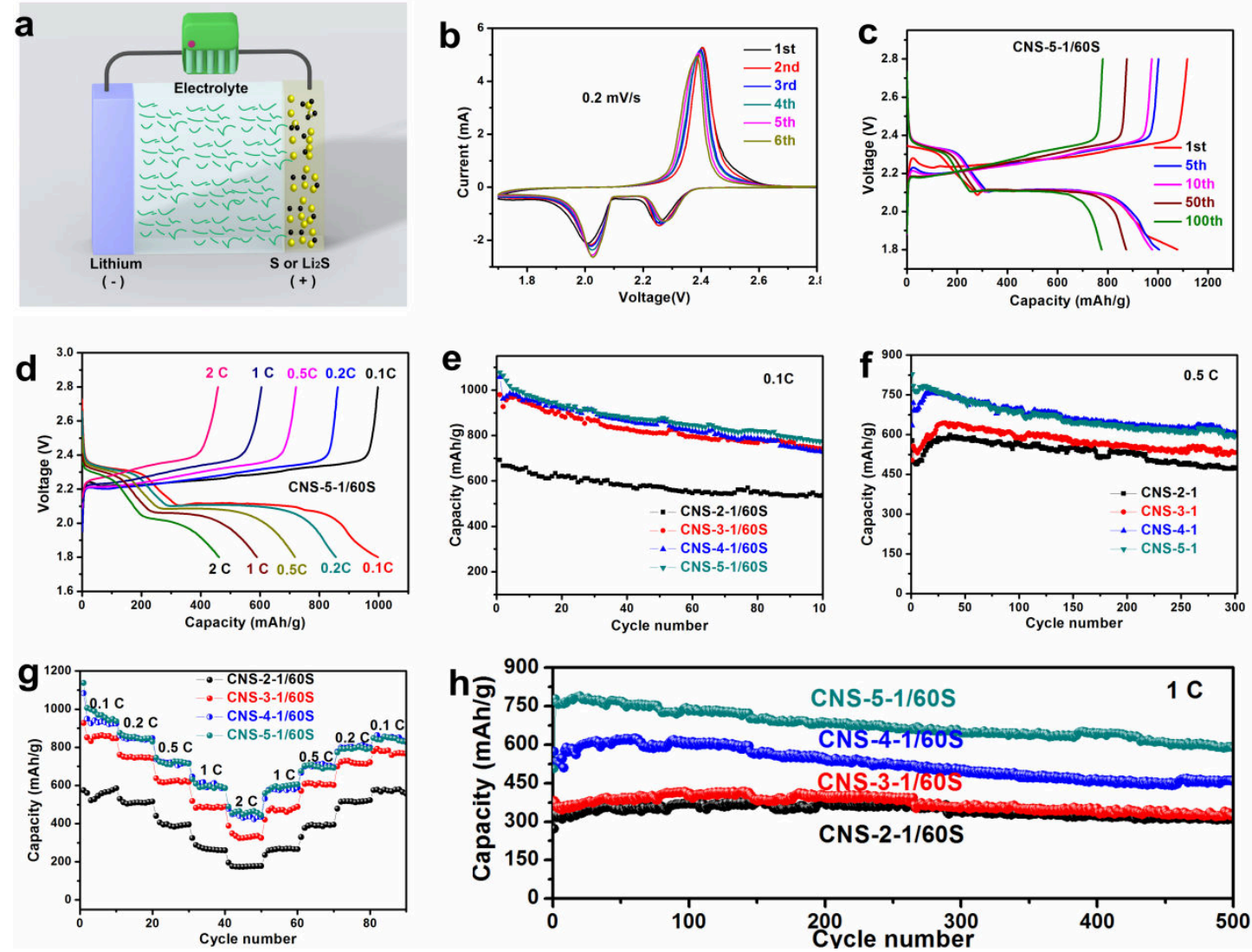

Figure 9. Electrochemical characterization of assembling lithium-sulfur batteries devices based on various CNS materials. a) Schematic illustration of the device configuration. b) CV curves of CNS-5-1/60S measured between 1.7 and $2.8 \mathrm{~V}^{2}$ versus $\mathrm{Li}^{+} / \mathrm{Li}$ at a sweep rate of $0.2 \mathrm{mV} \mathrm{s}^{-1}$. c) Charge-discharge profiles at a current density of $0.1 \mathrm{C}$ of CNS-5-1/60S cathode. d) Charge-discharge profiles at different rates of CNS-5-1/60S cathode. e) and f) are cycling performance curves of CNS-X-1/60S $(X=2,3,4,5)$ electrodes at the current density of $0.1 \mathrm{C}$ and $0.5 \mathrm{C}$, respectively. $\mathrm{g})$ The rate performance of CNS-X-1/60S(X=2, 3, 4, 5) electrodes. $\mathrm{h})$ The long cycling performance of CNS-X-1/60S $(X=2,3,4,5)$ electrodes at the $1 \mathrm{C}$ rate.

Electrochemical characterization was conducted to investigate the specific performance of the prepared electrodes in lithium-sulfur batteries. Figure 9a shows the structure of the assembled lithium-sulfur batteries using $\mathrm{Li}$ foil as anode and 
CNS-X-1/ $\lambda \mathrm{S}$ composites as a cathode. Firstly, the electrochemistry of the CNS-5-1/60S electrode was studied by CV curves in the voltage range of 1.7 to $2.8 \mathrm{~V}$ at $0.2 \mathrm{mV} \mathrm{s}^{-1}$ (Figure 9b). The CNS-5-1/60S electrode anodic peak is the typical CV profile of carbon/sulfur composite. A pair of cathodic peaks at $\sim 2.29$ and $\sim 2.04 \mathrm{~V}$ are related to the multiple reduction of $\mathrm{S}$ to $\mathrm{Li}_{2} \mathrm{~S}_{\mathrm{x}}(1<\mathrm{x}<8)$ : the first peak illustrates the reaction of $\mathrm{S}$ to soluble $\mathrm{Li}$ polysulfide $(4<\mathrm{x}<8)$ and the second peak can be attributed to the further reduction of these $\mathrm{Li}$ polysulfides to insoluble $\mathrm{Li}_{2} \mathrm{~S}_{\mathrm{x}}(\mathrm{x}=1$ or 2)[39]. An anodic peak at $\sim 2.40 \mathrm{~V}$ is assigned to the consecutive oxidation of $\operatorname{Li}_{2} \mathrm{~S}_{\mathrm{X}}$ ( $\mathrm{x}$ $=1$ or 2$)$ to the high order polysulfide $\left(\mathrm{Li}_{2} \mathrm{~S}_{8}\right)$ or $\mathrm{S}_{8}[40]$. After 5 cycles, peak separations slightly decreased, which illustrates the excellent cycling stability of CNS-5-1/60S electrode. Figure 9c shows the GCD curves of CNS-5-1/60S electrode at $0.1 \mathrm{C}$, which shows up to an initial capacity of $1078 \mathrm{mAh} \mathrm{g}^{-1}$ and two discharge plateaus fitting to the above-mentioned CV results. It is mentioned that the peak of the solid electrolyte interface (SEI) layer hasn't appeared in the first discharge cycle, which attributes the safety working potential of electrolyte $(1.7 \sim 2.8 \mathrm{~V})$ in Lithium-sulfur batteries[41-43]; Moreover, although polysulfide and lithium produce trace SEI layers in lithium-sulfur batteries, the SEI layers is instability because of the reaction complexity and soluble polysulfides in Lithium-sulfur batteries. After 5 cycles, the discharge capacity has a slight attenuation and decreased to $1005 \mathrm{mAh} \mathrm{g}^{-1}$. After 100 cycles, CNS-5-1/60S electrode can still indicate $775 \mathrm{mAh} \mathrm{g} \mathrm{g}^{-1}$ discharge capacity and $779 \mathrm{mAh} \mathrm{g}^{-1}$ charge capacity, which illustrates a stable coulombic efficiency for CNS-5-1/60S electrode. To investigate the rate performance of 
CNS-5-1/60S composite, the GCD curves at different C are shown in Figure 9d, and the discharge capacities are $997,862,721$ and $605 \mathrm{mAh} \mathrm{g}^{-1}$ at $0.1,0.2,0.5$ and $1 \mathrm{C}$, respectively. Moreover, even at 2C, the discharge/charge capacity of 458 (461) mAh $\mathrm{g}^{-1}$ can be obtained, which illustrated the better performance of CNS-5-/60S electrode. Figure 9e shows the cycling performance at $0.1 \mathrm{C}$ of $\mathrm{CNS}-\mathrm{X}-1 / \mathrm{S}(\mathrm{X}=2,3,4,5)$ electrodes with $60 \%$ sulfur content. The CNS-2-1/60S electrode exhibits the only an initial capacity of $536 \mathrm{mAh} \mathrm{g}^{-1}$ in comparison with CNS-3-1/60S (979 $\mathrm{mAh} \mathrm{g}^{-1}$ ), CNS-4-1/60S (1058 $\left.\mathrm{mAh} \mathrm{g}^{-1}\right)$ and CNS-5-1/60S (1078 $\left.\mathrm{mAh} \mathrm{g}^{-1}\right)$. After 100 cycles, the CNS-2-1/60S electrode shows a discharge capacity of $536 \mathrm{mAh} \mathrm{g}^{-1}$. This is due to the limited pore volume in CNS-2-1 (1.17 $\mathrm{cm}^{3} \mathrm{~g}^{-1}$, Supplementary materials Table S2)) because the large amount of sulfur cannot be effectively anchored in carbon carrier and further form dissolved polysulfides. The cycling performance of CNS-X-1/S electrodes at $0.5 \mathrm{C}$ was investigated, and the results are shown in Figure 9f. After all the samples experiencing an activation process[44], the highest capacities of CNS-X-1/S $(\mathrm{X}=2,3,4,5)$ were 588, 644,760 and $780 \mathrm{mAh} \mathrm{g}^{-1}$, respectively. After all electrodes were cycled for 300 cycles, CNS-X-1/S $(\mathrm{X}=2,3,4,5)$ show a capacity of 472, 532, 606 and $595 \mathrm{mAh} \mathrm{g}^{-1}$, respectively. To investigate the reversibility of CNS materials, we conducted the rate performance evaluations of CNS-X-1/S (X=2, 3, 4, 5). As shown in Figure $9 \mathrm{~g}$, it is clear that CNS-5-1/60S and CNS-4-1/60S can keep good reversibility as compared with other electrodes because of their larger pore volume and fast ion diffusion channels. In particular, CNS-5-1 electrode can obtain a capacity of $848 \mathrm{mAh} \mathrm{g}^{-1}$ in comparison with the second discharge capacity (1006 mAh 
$\mathrm{g}^{-1}$ ) at the $0.1 \mathrm{C}$. This result demonstrates an excellent reversibility of CNS-5-1/60S as a cathodic material. Figure $9 \mathrm{~h}$ further shows the long-term cycling performance of CNS-X-1/S $(\mathrm{X}=2,3,4,5)$ cathode at $1 \mathrm{C}$, indicating an excellent cycling stability. The capacity of CNS-5-1/60S (excluding the first activation capacity) was as high as $779 \mathrm{mAh} \mathrm{g}^{-1}$ and retained $75 \%$ of the initial capacity after 500 cycles with an ultralow capacity attenuation of $0.048 \%$. Although CNS-4-1/60S shows a similar capacity with CNS-5-1/60S at low rate, CNS-5-1/60S exhibited better performance than CNS-4-1/60S. This result could be attributed to higher pore volume $\left(2.15 \mathrm{~cm}^{3} \mathrm{~g}^{-1}\right)$ and mesopores in CNS-5-1 than those in CNS-4-1, which provides more ion diffusion channels and further contributes to the improvement of the electronic reaction kinetics. Overall, the excellent electrochemical performance of CNS-5-1/60S could be attributed to the synergy effect of the confining of polysulfides by micropores and 2D conductivity network of sheet structure to accelerate the fast ion diffusion. Moreover, we systematically compared carbon nanosheets as host materials for sulfur cathodes (Supplementary materials Table S4), and these results further validate the excellent electrochemical performance of our prepared carbon nanosheets in lithium-sulfur 
batteries.
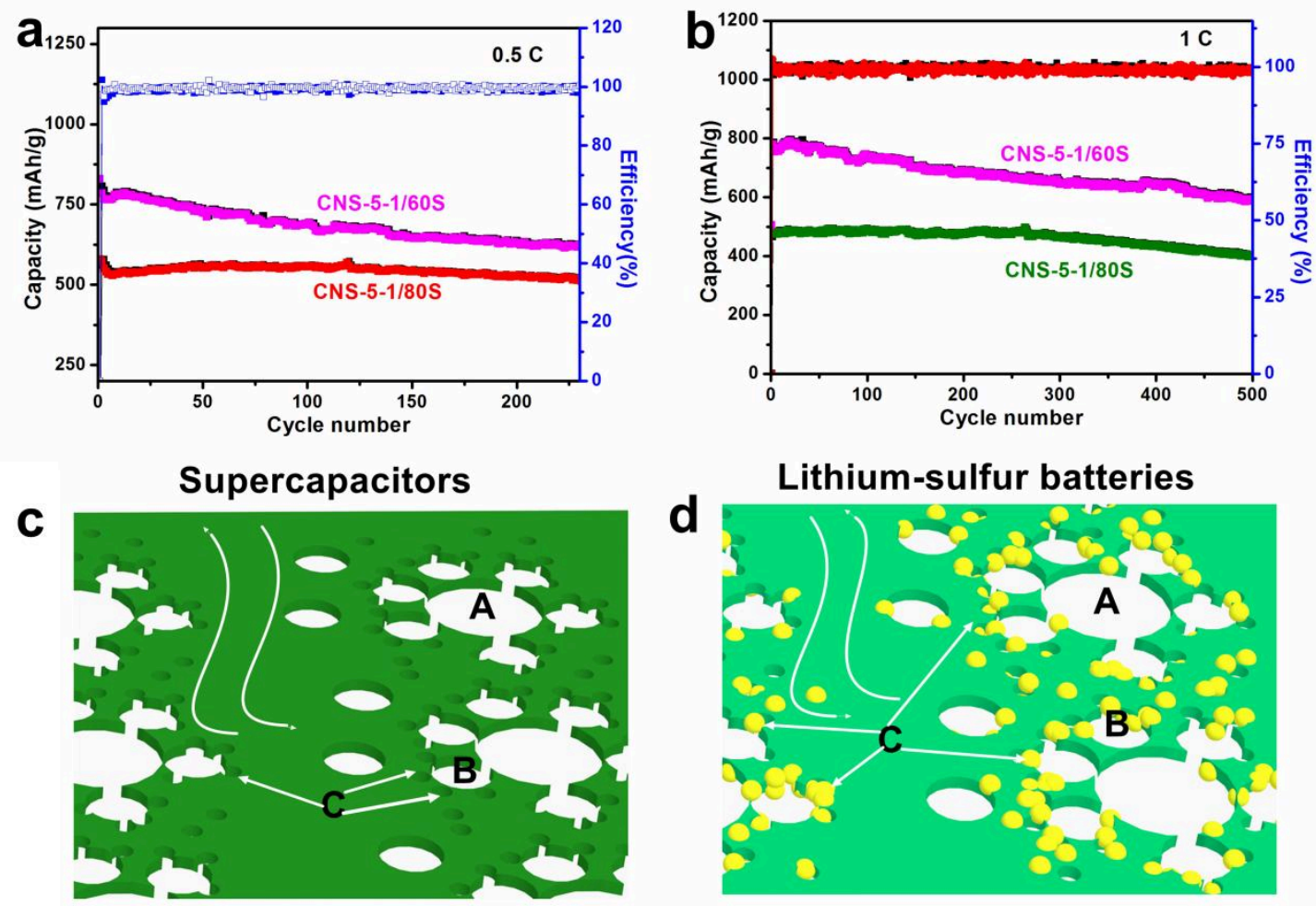

\section{A: Electrolyte storage area \\ B: Ion transportation channels \\ C:Electron ad-desorption area}

A: loading sulfur and electrolyte area

B: $\mathrm{Li}^{+}$transportation channels

C: Anchor sites of $\mathrm{S}$ and polysulfides

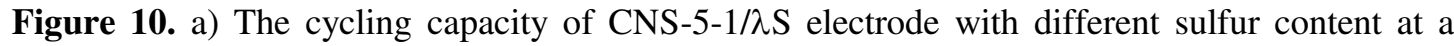
constant current density of $0.5 \mathrm{C}$. b) The cycling capacity of CNS-5-1 as electrode host materials at different sulfur content of 1 C. c) and d) The microstructure of CNS in SCs and lithium-sulfur batteries.

Finally, we investigated the cycling performance with a higher proportion of sulfur content in CNS-5-1. The cycling performance of CNS-5-1/ $\lambda$ S electrode with different sulfur contents are shown in Figure 10a, and stable cycling performance and columbic efficiency can be seen even in CNS-5-1 loading up to $80 \%$ sulfur. An initial capacity of CNS-5-1/80S indicates a $578 \mathrm{mAh} \mathrm{g}^{-1}$ at $0.5 \mathrm{C}$, and it retained $91 \%$ of the initial capacity after 200 cycles at an ultralow degradation of $0.045 \%$. Even when the rate increased to $1 \mathrm{C}$, CNS-5-1/80S can obtain a $493 \mathrm{mAh} \mathrm{g}^{-1}$ initial capacity, and after 
500 cycles, the remained $403 \mathrm{mAh} \mathrm{g}^{-1}$ discharge capacity can be sustained (Figure 10b). Moreover, the high loading mass of CNS-5-1/60S cathode were assembled (Figure S9), and its cycling performance shows that even up $1.9 \mathrm{mg} / \mathrm{cm}^{2}$ sulfur content, a intial $1078 \mathrm{maAh} \mathrm{g}^{-1}$ can be obtained after 100 cycles a $846 \mathrm{mAh} \mathrm{g}^{-1}$ capacity can be retained. Figure 10c illustrates the microstructure of CNS with hierarchically interconnected pores, including micropores(C), mesopores (B) and macropores (A). The macropores play a role in storing electrolyte, and mesopores act as an ion transportation channel to accelerate the ion diffusion, and a large number of micropores act as ad-desorption sites of electrons contributing the high capacitance[14]. Moreover, The unique sheet structure of CNS materials further improves the transportation abilities of electrons[45]. Their co-working effect contributes the excellent performance when CNS is used as electrode materials in SCs. Figure 10d shows the micromorphology of CNS/S hybrids. In lithium-sulfur batteries, the macropores can not only provide a place to electrolyte storage but also can host sulfur. Mesopores provides convenient channels to transport ions, and micropores can act as anchor sites to prevent the active materials ( $S$ and polysulfides) from dissolving[21]. The unique hierarchically interconnected pores and sheet structure result in the high capacity and excellent rate performance in lithium-sulfur batteries.

\section{Conclusions}

In summary, we successfully synthesised a new type of CNS with an abundant porous structure, unique ultrathin nanosheet structure and an ultrahigh SSA by carbonization and $\mathrm{KOH}$ stripping process for biomass-derived sheet. The SSA and the specific pore 
diameter distribution of CNS can be tailored by changing the activator content. CNS-4-1 shows a high capacitance of $300 \mathrm{~F} \mathrm{~g}^{-1}$ at $0.25 \mathrm{~A} \mathrm{~g}^{-1}$ with 3-electrode configuration in aqueous electrolyte. When it was assembled to SC devices, an energy density of $91 \mathrm{Wh} \mathrm{kg}^{-1}$ was obtained at a power density of $200 \mathrm{~W} \mathrm{~kg}^{-1}$ (retains $49 \mathrm{Wh}$ $\mathrm{kg}^{-1}$ at $4.9 \mathrm{~kW} \mathrm{~kg}^{-1}$ ) in ionic liquids. In addition, CNS-5-1 also shows a $586 \mathrm{mAh} \mathrm{g}^{-1}$ reversible capacity and an almost $100 \%$ coulombic efficiency after 500 cycles at a rate of $1 \mathrm{C}$ in lithium-sulfur batteries. The excellent electrochemical performance of CNS as electrode materials are attributed to short diffusion channel and fast ion reaction kinetics obtained from their unique structure of ultrathin nanosheet morphology and ultrahigh SSA. More importantly, the preparation of CNS required only pyrolysis and activation process, and the carbonized biomass precursor is sustainable and abundant in the earth, which means that CNS can be fabricated in large scale and further provides a potential application in energy storage.

\section{ACKNOWLEDGMENTS}

This work was financially supported by the National Natural Science Foundation ofC hina (Nos.51202150, 51272161,21703141), Program of Introducing Innovative Resea rch Team in Dongguan (No.2014607109), Shenzhen Basic Research Program (No. JC YJ20170817102025753).

\section{References}

[1] H. Wang, Z. Xu, A. Kohandehghan, Z. Li, K. Cui, X. Tan, T.J. Stephenson, C.K. King'ondu, C.M. Holt, B.C. Olsen, J.K. Tak, D. Harfield, A.O. Anyia, D. Mitlin, Interconnected carbon nanosheets derived from hemp for ultrafast supercapacitors with high energy, ACS Nano 7(6) (2013) 5131-41. 
[2] Y. He, X. Zhuang, C. Lei, L. Lei, Y. Hou, Y. Mai, X. Feng, Porous carbon nanosheets: Synthetic strategies and electrochemical energy related applications, Nano Today 24 (2019) 103-119.

[3] Y. Sakamoto, M. Kaneda, O. Terasaki, D.Y. Zhao, J.M. Kim, G. Stucky, H.J. Shin, R. Ryoo, Direct imaging of the pores and cages of three-dimensional mesoporous materials, Nature 408(6811) (2000) 449-53.

[4] P. Simon, Y. Gogotsi, Materials for electrochemical capacitors, Nat. Mater. 7 (2008) 845.

[5] Z. Li, H.B. Wu, X.W. Lou, Rational designs and engineering of hollow micro-/nanostructures as sulfur hosts for advanced lithium-sulfur batteries, Energ. Environ. Sci. 9(10) (2016) 3061-3070.

[6] H. Jiang, J. Gu, X. Zheng, M. Liu, X. Qiu, L. Wang, W. Li, Z. Chen, X. Ji, J. Li, Defect-rich and ultrathin $\mathrm{N}$ doped carbon nanosheets as advanced trifunctional metal-free electrocatalysts for the ORR, OER and HER, Energ. Environ. Sci. 12(1) (2019) 322-333.

[7] L. Yao, Q. Wu, P. Zhang, J. Zhang, D. Wang, Y. Li, X. Ren, H. Mi, L. Deng, Z. Zheng, Scalable 2D Hierarchical Porous Carbon Nanosheets for Flexible Supercapacitors with Ultrahigh Energy Density, Adv. Mater. 30(11) (2018) 1706054.

[8] K. Zhao, S. Liu, G. Ye, Q. Gan, Z. Zhou, Z. He, High-yield bottom-up synthesis of 2D metal-organic frameworks and their derived ultrathin carbon nanosheets for energy storage, J. Mate. Chem. A 6(5) (2018) 2166-2175.

[9] J. Hou, C. Cao, F. Idrees, X. Ma, Hierarchical porous nitrogen-doped carbon nanosheets derived from silk for ultrahigh-capacity battery anodes and supercapacitors, ACS Nano 9(3) (2015) 2556-64.

[10] J. Ding, H. Wang, Z. Li, A. Kohandehghan, K. Cui, Z. Xu, B. Zahiri, X. Tan, E.M. Lotfabad, B.C. Olsen, D. Mitlin, Carbon nanosheet frameworks derived from peat moss as high performance sodium ion battery anodes, ACS Nano 7(12) (2013) 11004-15.

[11] F. Pan, Z. Cao, Q. Zhao, H. Liang, J. Zhang, Nitrogen-doped porous carbon nanosheets made from biomass as highly active electrocatalyst for oxygen reduction reaction, J. Power Sources 272 (2014) 8-15.

[12] Y. Yao, Q. Zhang, P. Liu, L. Yu, L. Huang, S.-Z. Zeng, L. Liu, X. Zeng, J. Zou, Facile synthesis of high-surface-area nanoporous carbon from biomass resources and its application in supercapacitors, RSC Adv. 8(4) (2018) 1857-1865.

[13] C. Wang, D. Wu, H. Wang, Z. Gao, F. Xu, K. Jiang, Nitrogen-doped two-dimensional porous carbon sheets derived from clover biomass for high performance supercapacitors, J. Power Sources 363 (2017) 375-383.

[14] C. Chen, D. Yu, G. Zhao, B. Du, W. Tang, L. Sun, Y. Sun, F. Besenbacher, M. $\mathrm{Yu}$, Three-dimensional scaffolding framework of porous carbon nanosheets derived from plant wastes for high-performance supercapacitors, Nano Energy 27 (2016) 377-389.

[15] C. Wang, D. Wu, H. Wang, Z. Gao, F. Xu, K. Jiang, Biomass derived nitrogen-doped hierarchical porous carbon sheets for supercapacitors with high performance, J. Colloid Interface Sci. 523 (2018) 133-143. 
[16] Z. Ling, Z. Wang, M. Zhang, C. Yu, G. Wang, Y. Dong, S. Liu, Y. Wang, J. Qiu, Sustainable Synthesis and Assembly of Biomass-Derived B/N Co-Doped Carbon Nanosheets with Ultrahigh Aspect Ratio for High-Performance Supercapacitors, Adv. Funct. Mater. 26(1) (2016) 111-119.

[17] Y. Wu, J.-P. Cao, X.-Y. Zhao, Z.-Q. Hao, Q.-Q. Zhuang, J.-S. Zhu, X.-Y. Wang, X.-Y. Wei, Preparation of porous carbons by hydrothermal carbonization and $\mathrm{KOH}$ activation of lignite and their performance for electric double layer capacitor, Electrochim. Acta 252 (2017) 397-407.

[18] q. zhang, K. Han, S. Li, M. Li, J. Li, K. Ren, Synthesis of Garlic Skin-Derived 3D Hierarchical Porous Carbon for High-Performance Supercapacitors, Nanoscale 10(5) (2018) 2427-2437.

[19] J. Zou, P. Liu, L. Huang, Q. Zhang, T. Lan, S. Zeng, X. Zeng, L. Yu, S. Liu, H. $\mathrm{Wu}, \mathrm{W}$. Tu, Y. Yao, Ultrahigh-content nitrogen-decorated nanoporous carbon derived from metal organic frameworks and its application in supercapacitors, Electrochim. Acta 271 (2018) 599-607.

[20] M. Oschatz, L. Borchardt, K. Pinkert, S. Thieme, M.R. Lohe, C. Hoffmann, M. Benusch, F.M. Wisser, C. Ziegler, L. Giebeler, M.H. Rümmeli, J. Eckert, A. Eychmüller, S. Kaskel, Hierarchical Carbide-Derived Carbon Foams with Advanced Mesostructure as a Versatile Electrochemical Energy-Storage Material, Adv. Energy Mater. 4(2) (2014) 1300645.

[21] Y. Yao, P. Liu, Q. Zhang, S. Zeng, S. Chen, G. Zou, J. Zou, X. Zeng, X. Li, Nitrogen-doped micropores binder-free carbon-sulphur composites as the cathode for long-life lithium-sulphur batteries, Mater. Lett. 231 (2018) 159-162.

[22] K. Liao, S. Chen, H. Wei, J. Fan, Q. Xu, Y. Min, Micropores of pure nanographite spheres for long cycle life and high-rate lithium-sulfur batteries, J. Mate. Chem. A 6(45) (2018) 23062-23070.

[23] Z. Li, J. Zhang, B. Guan, D. Wang, L.-M. Liu, X.W. Lou, A sulfur host based on titanium monoxide@carbon hollow spheres for advanced lithium-sulfur batteries, Nat. Comm. 7 (2016) 13065.

[24] L. Qie, W. Chen, H. Xu, X. Xiong, Y. Jiang, F. Zou, X. Hu, Y. Xin, Z. Zhang, Y. Huang, Synthesis of functionalized 3D hierarchical porous carbon for high-performance supercapacitors, Energ. Environ. Sci. 6(8) (2013) 2497.

[25] Y. Xu, C.Y. Chen, Z. Zhao, Z. Lin, C. Lee, X. Xu, C. Wang, Y. Huang, M.I. Shakir, X. Duan, Solution Processable Holey Graphene Oxide and Its Derived Macrostructures for High-Performance Supercapacitors, Nano. Lett. 15(7) (2015) 4605-10.

[26] Y. Li, N. Yu, P. Yan, Y. Li, X. Zhou, S. Chen, G. Wang, T. Wei, Z. Fan, Fabrication of manganese dioxide nanoplates anchoring on biomass-derived cross-linked carbon nanosheets for high-performance asymmetric supercapacitors, J. Power Sources 300 (2015) 309-317.

[27] B. Lu, J. Zhou, Y. Song, H. Wang, W. Xiao, D. Wang, Molten-salt treatment of waste biomass for preparation of carbon with enhanced capacitive properties and electrocatalytic activity towards oxygen reduction, Faraday Discuss 190 (2016) 147-59. 
[28] S. Lei, L. Chen, W. Zhou, P. Deng, Y. Liu, L. Fei, W. Lu, Y. Xiao, B. Cheng, Tetra-heteroatom self-doped carbon nanosheets derived from silkworm excrement for high-performance supercapacitors, J.Power Sources 379 (2018) 74-83.

[29] J. Nan, Y. Shi, Z. Xiang, S. Wang, J. Yang, B. Zhang, Ultrathin NiCo2O4 nanosheets assembled on biomass-derived carbon microsheets with polydopamine for high-performance hybrid supercapacitors, Electrochim. Acta 301 (2019) 107-116.

[30] P.G. Bruce, S.A. Freunberger, L.J. Hardwick, J.M. Tarascon, Li-O2 and Li-S batteries with high energy storage, Nat. Mater. 11(1) (2011) 19-29.

[31] X. Ji, K.T. Lee, L.F. Nazar, A highly ordered nanostructured carbon-sulphur cathode for lithium-sulphur batteries, Nat. Mater. 8(6) (2009) 500-6.

[32] F. Xu, Z. Tang, S. Huang, L. Chen, Y. Liang, W. Mai, H. Zhong, R. Fu, D. Wu, Facile synthesis of ultrahigh-surface-area hollow carbon nanospheres for enhanced adsorption and energy storage, Nat. Commun. 6 (2015) 7221.

[33] Y.S. Su, A. Manthiram, Lithium-sulphur batteries with a microporous carbon paper as a bifunctional interlayer, Nat. Commun. 3 (2012) 1166.

[34] J.S. Yeon, S. Yun, J.M. Park, H.S. Park, Surface-Modified Sulfur Nanorods Immobilized on Radially Assembled Open-Porous Graphene Microspheres for Lithium-Sulfur Batteries, ACS Nano (2019).

[35] L. Feng, K. Wang, X. Zhang, X. Sun, C. Li, X. Ge, Y. Ma, Flexible Solid-State Supercapacitors with Enhanced Performance from Hierarchically Graphene Nanocomposite Electrodes and Ionic Liquid Incorporated Gel Polymer Electrolyte, Adv. Funct. Mater. 28(4) (2018) 1704463.

[36] W. Tian, Q. Gao, L. Zhang, C. Yang, Z. Li, Y. Tan, W. Qian, Z. Hang, Renewable graphene-like nitrogen-doped carbon nanosheets as supercapacitor electrodes with integrated high energy-power properties, J. Mater. Chem. A 4(22) (2016) 8690-8699.

[37] C. Zu, A. Manthiram, Hydroxylated Graphene-Sulfur Nanocomposites for High-Rate Lithium-Sulfur Batteries, Adv. Energy Mater.3(8) (2013) 1008-1012.

[38] F. Wu, Y. Ye, R. Chen, J. Qian, T. Zhao, L. Li, W. Li, A Systematic Effect for an Ultra-long Cycle Lithium-sulfur Battery, Nano Lett. 15(11) (2015) 7431.

[39] S. Zhang, M. Zheng, Z. Lin, N. Li, Y. Liu, B. Zhao, H. Pang, J. Cao, P. He, Y. Shi, Activated carbon with ultrahigh specific surface area synthesized from natural plant material for lithium-sulfur batteries, J. Mater. Chem. A 2(38) (2014) 15889-15896.

[40] J.-Q. Huang, Q. Zhang, H.-J. Peng, X.-Y. Liu, W.-Z. Qian, F. Wei, Ionic shield for polysulfides towards highly-stable lithium-sulfur batteries, Energ. Environ. Sci. 7(1) (2014) 347-353.

[41] K. Edström, M. Herstedt, D.P. Abraham, A new look at the solid electrolyte interphase on graphite anodes in Li-ion batteries, J. Power Sources 153(2) (2006) 380-384.

[42] H. Wu, G. Chan, J.W. Choi, I. Ryu, Y. Yao, M.T. Mcdowell, S.W. Lee, A. Jackson, Y. Yang, L. Hu, Stable cycling of double-walled silicon nanotube battery anodes through solid-electrolyte interphase control, Nat. Nanotechnol. 7(5) (2012) 310-315. 
[43] L.F. Cui, Y. Yang, C.M. Hsu, Y. Cui, Carbon-silicon core-shell nanowires as high capacity electrode for lithium ion batteries, Nano Lett. 9(9) (2009) 3370-3374. [44] S.-Z. Zeng, X. Zeng, W. Tu, Y. Yao, L. Yu, H. Wu, W. Jin, H. Huang, J. Zou, Facile and tailored synthesis of ultrahigh-surface-area clews of carbon nanobelts for high-rate lithium-sulfur batteries, J. Mater. Chem. A 5(44) (2017) 23209-23220.

[45] C. Long, X. Chen, L. Jiang, L. Zhi, Z. Fan, Porous layer-stacking carbon derived from in-built template in biomass for high volumetric performance supercapacitors, Nano Energy 12 (2015) 141-151. 
Here, we report a novel synthesis method of 2D hierarchical porous CNS with ultrahigh SSA $\left(2687 \mathrm{~m}^{2} \mathrm{~g}^{-1}\right)$ and ultrathin structure $(4 \mathrm{~nm})$ by directly pyrolysing and activating a unique and abundant biomass sheet. The electrochemical characterisations show that the prepared CNS-4-1 materials as electrodes creates a good energy-storage capability, with the energy density being $91 \mathrm{Wh} \mathrm{kg}^{-1}$ for symmetric SCs Besides, the CNS-5-1 also exhibits a high initial capacity of 1078 $\mathrm{mAh} \mathrm{g}^{-1}$ at $0.1 \mathrm{C}$ when it acted as a sulfur hosting material for lithium-sulfur batteries. More importantly, it also shows a $586 \mathrm{mAh} \mathrm{g}^{-1}$ reversible capacity after 500 cycles at a high rate of $1 \mathrm{C}$.

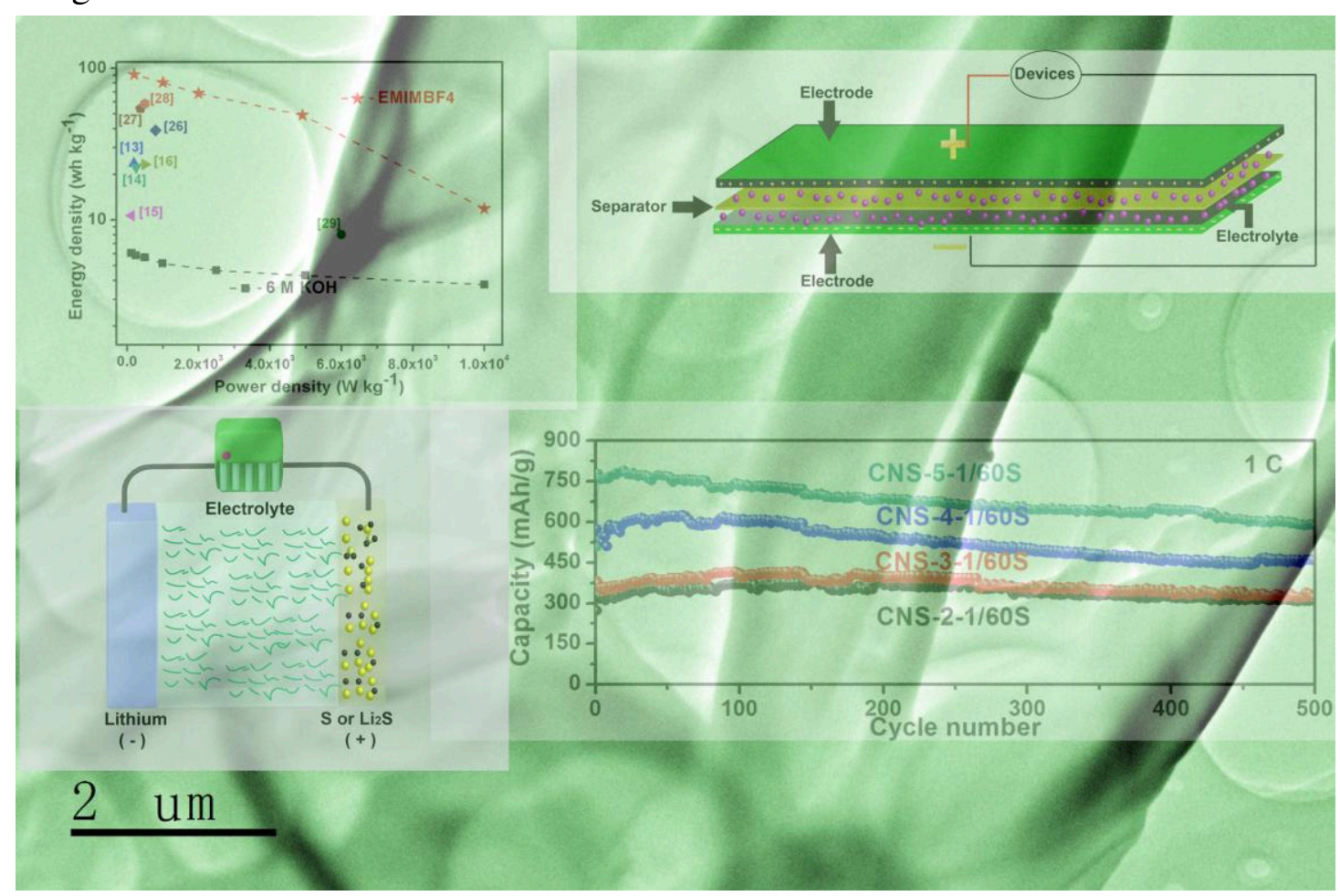




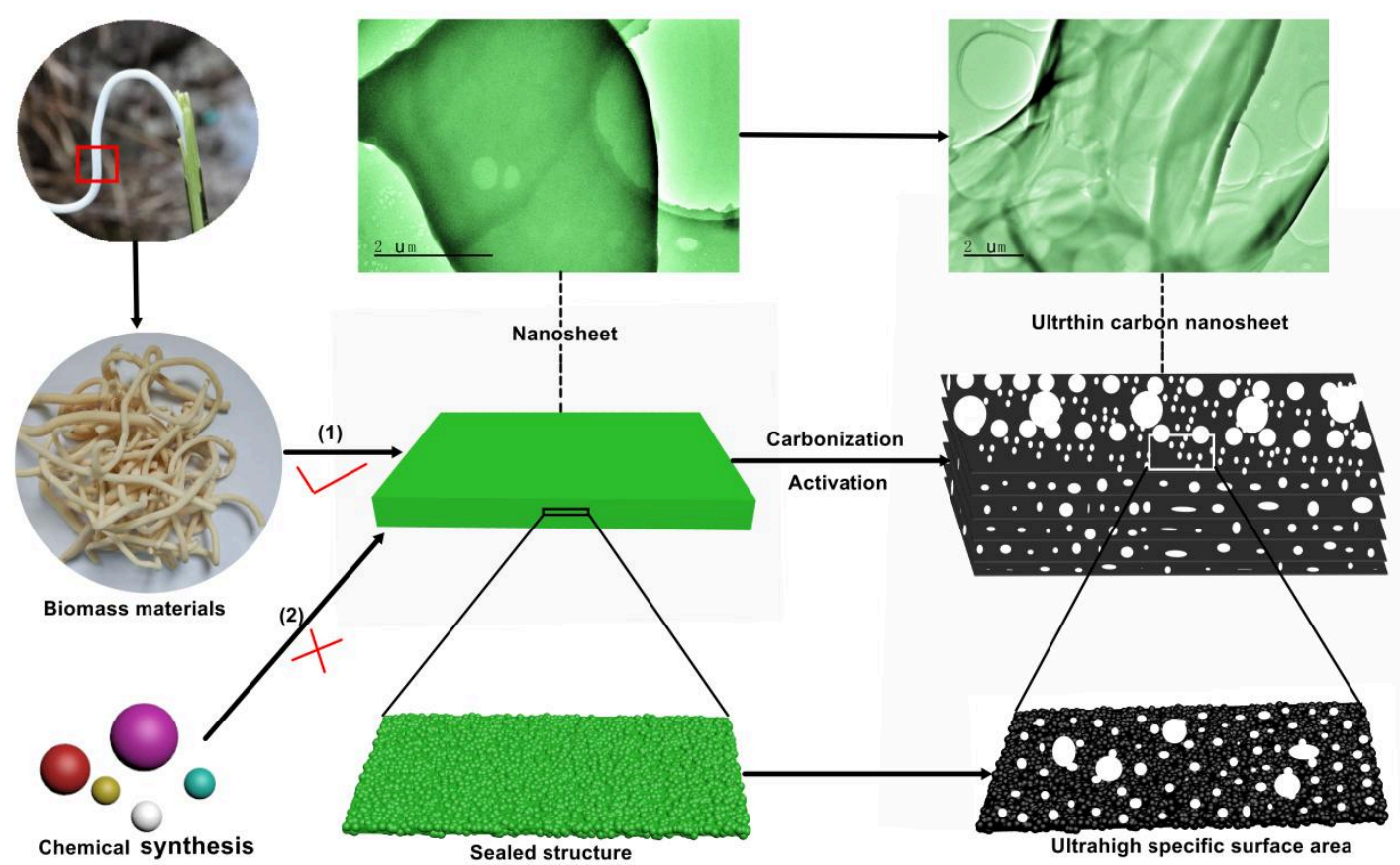

Figure 1 The schematic of synthesis of carbon nanosheets 

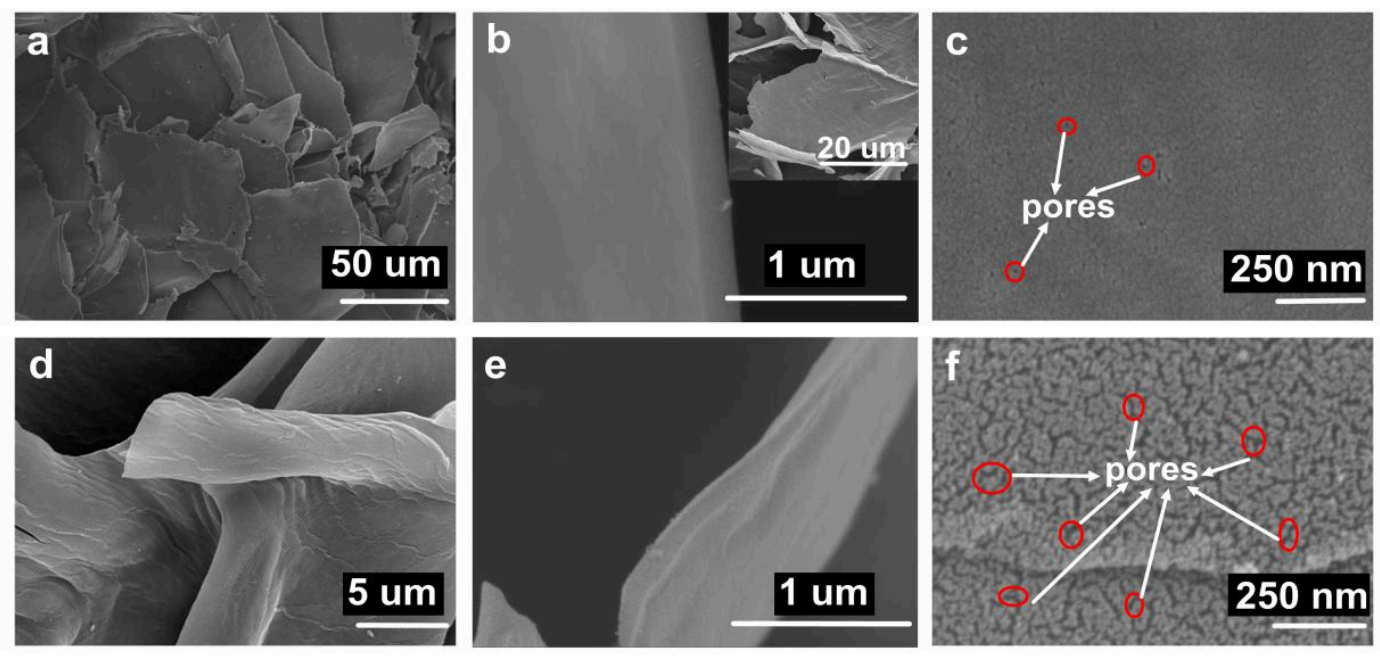

Figure 2. The SEM images of precursor (a), CNS (b-c) and CNS-5-1(d-f). 

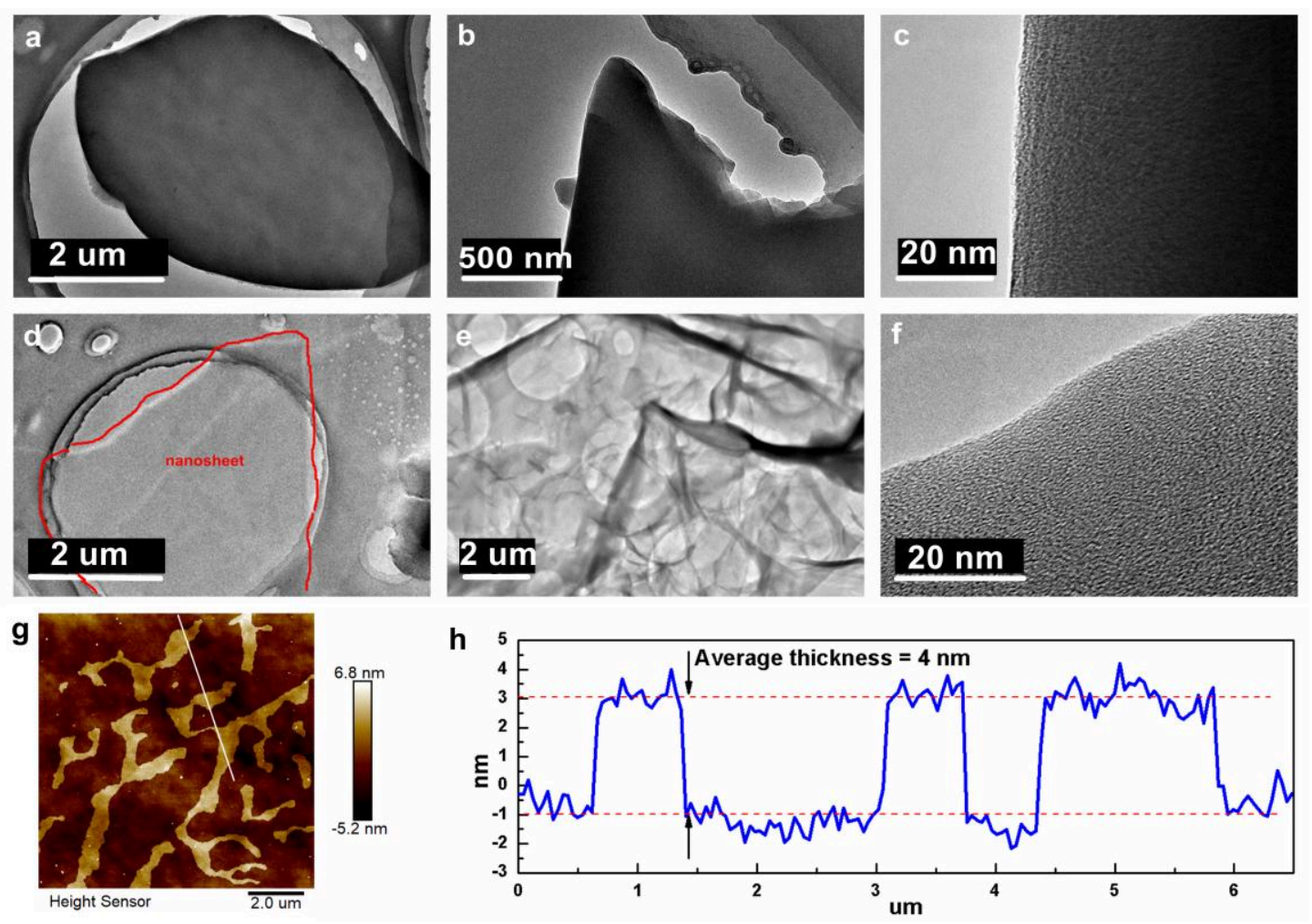

Figure 3.The TEM images of CNS (a-c) and CNS-5-1 (d-f). g) AFM image of CNS-5-1 on a Si substrate. h) The specific thickness of CNS-5-1 corresponding to the white line in Figure 3g. 

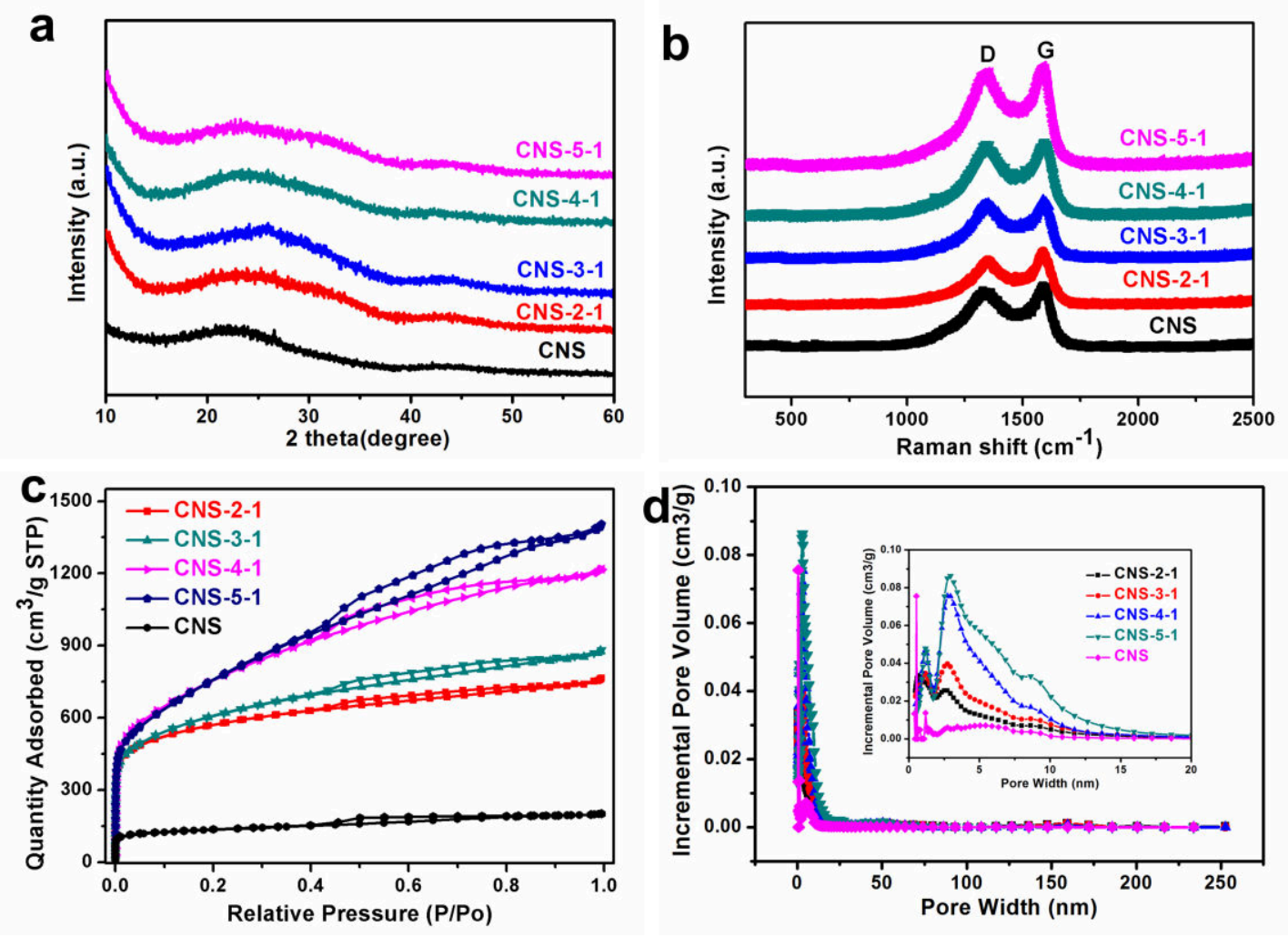

Figure 4. a) The $X$-Raw diffraction, b) Raman spectra, c) $\mathrm{N}_{2}$ de-adsorption isotherm and d) specific pore distribution curves of CNS and CNS-X $-1(X=2,3,4,5)$. 

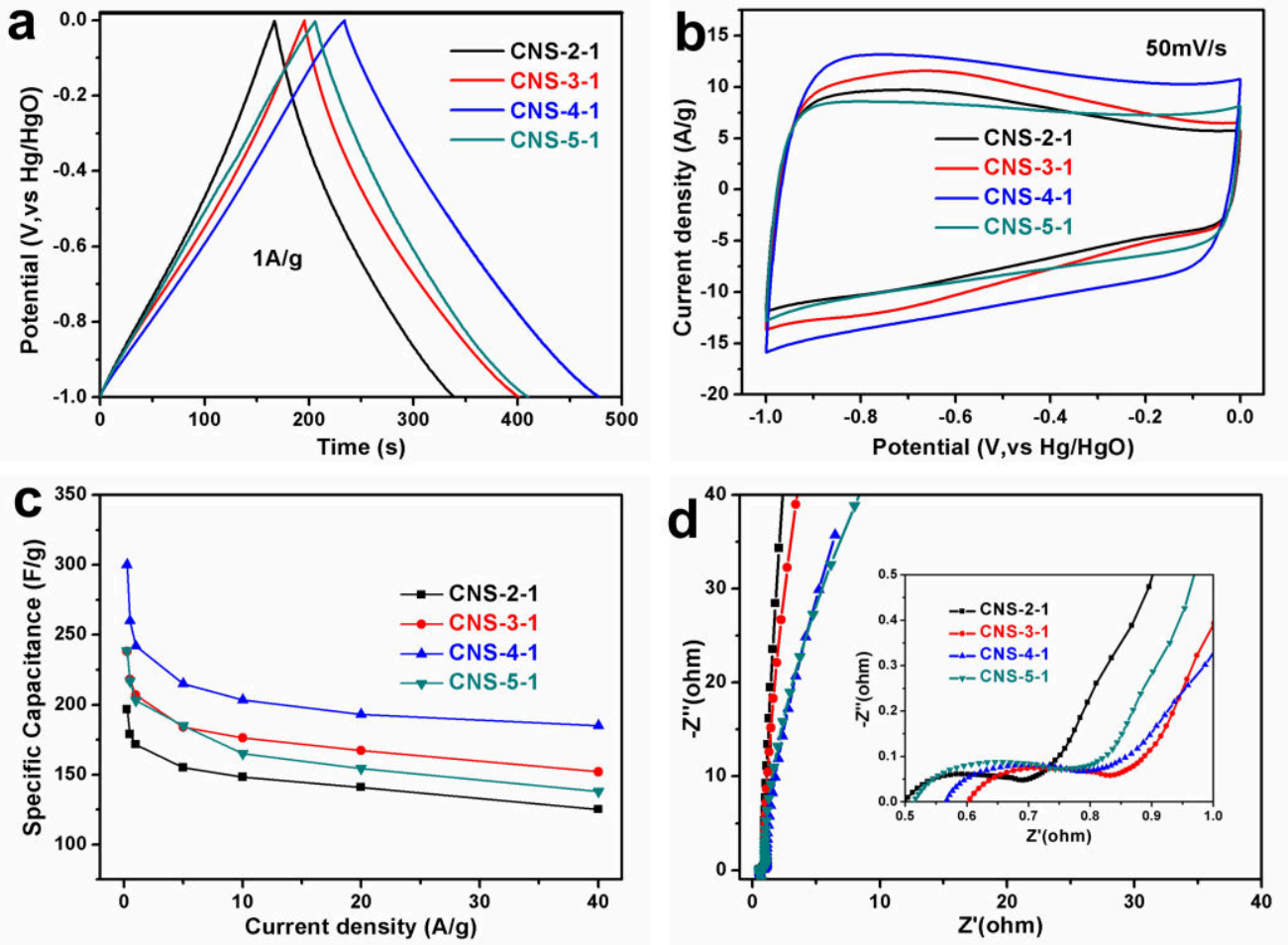

Figure 5. Electrochemical characterization of the CNS-X-1 $(X=2,3,4,5)$ as electrode materials with three-electrode configuration at $6 \mathrm{M} \mathrm{KOH}$ electrolyte. a) GCD curves for different CNS-X-1 $(\mathrm{X}=2,3,4,5)$ measured at $1 \mathrm{~A} \mathrm{~g}^{-1}$. b) $\mathrm{CV}$ curves for the CNS-X-1 $(\mathrm{X}=2,3,4,5)$ measured at 50 $\mathrm{mVs}^{-1}$. c) The specific capacitance of the electrodes as various current densities. d) The Nyquist plots of all samples. 
a
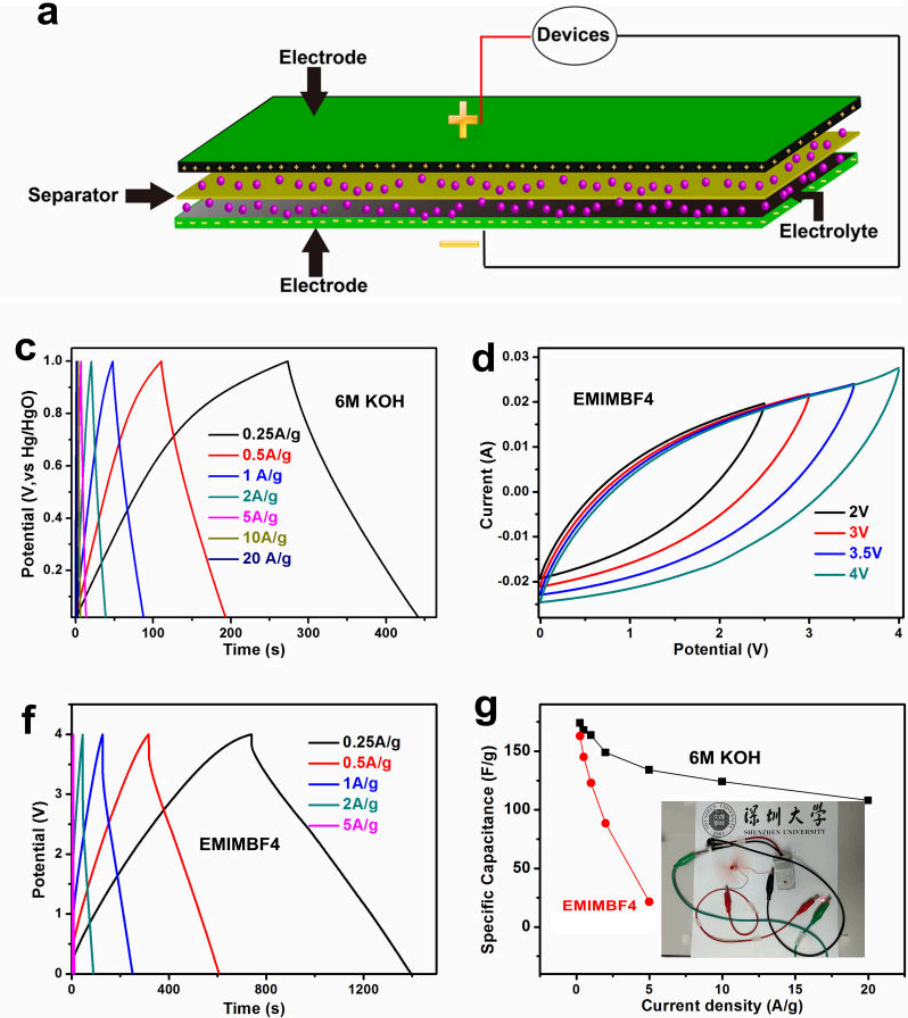
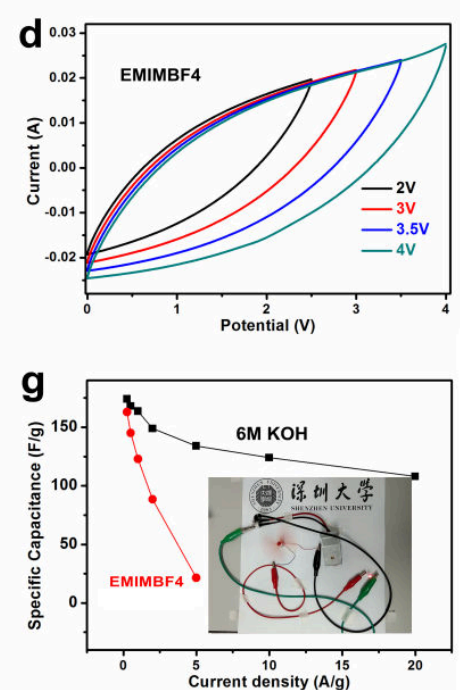
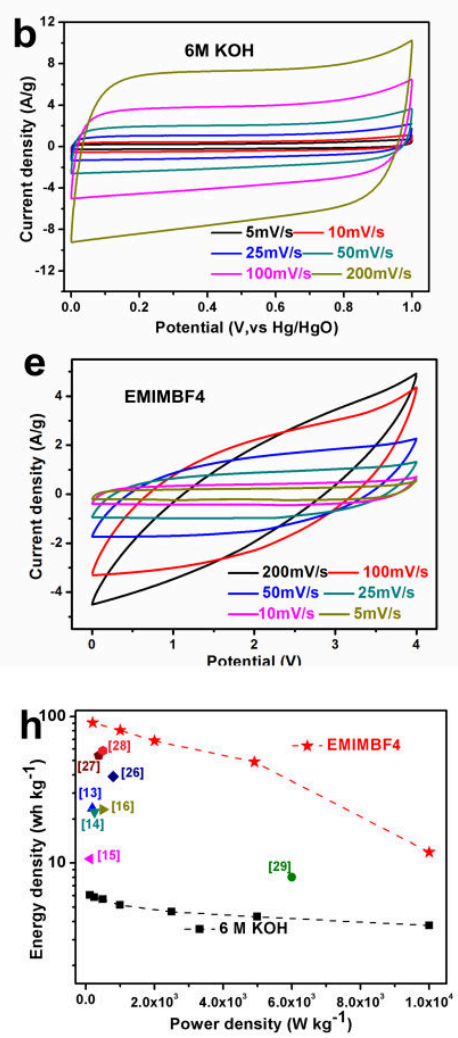

Figure 6. Electrochemical characterization of assembling SCs devices based on the CNS-4-1 with $6 \mathrm{M} \mathrm{KOH}$ and $\mathrm{EMIMBF}_{4}$ electrolyte. a) Schematic illustration of the device configuration. b) CV curves for the CNS-4-1-based SCs device at different scant rates (6 M KOH). c) GCD curves for the CNS-4-1-based SCs device measured at different current densities (6 M KOH). d) CV curves for the CNS-4-1-based SCs device at different scan window $\left(\mathrm{EMIMBF}_{4}\right)$. e) CV curves for the CNS-4-1-based SCs device at different scant rates $\left(\mathrm{EMIMBF}_{4}\right)$. f) GCD curves for the CNS-4-1-based SCs devices measured at different current densities $\left(\mathrm{EMIMBF}_{4}\right)$. g) Specific capacitance as a function of the current density (inner digital images: Photograph demonstrates that CNS-4-1-based SCs can light up LED and mini fan). h) Ragone plot for the CNS-4-1-based SCs with different electrolytes and a comparison with literature data relating to CNS materials. 

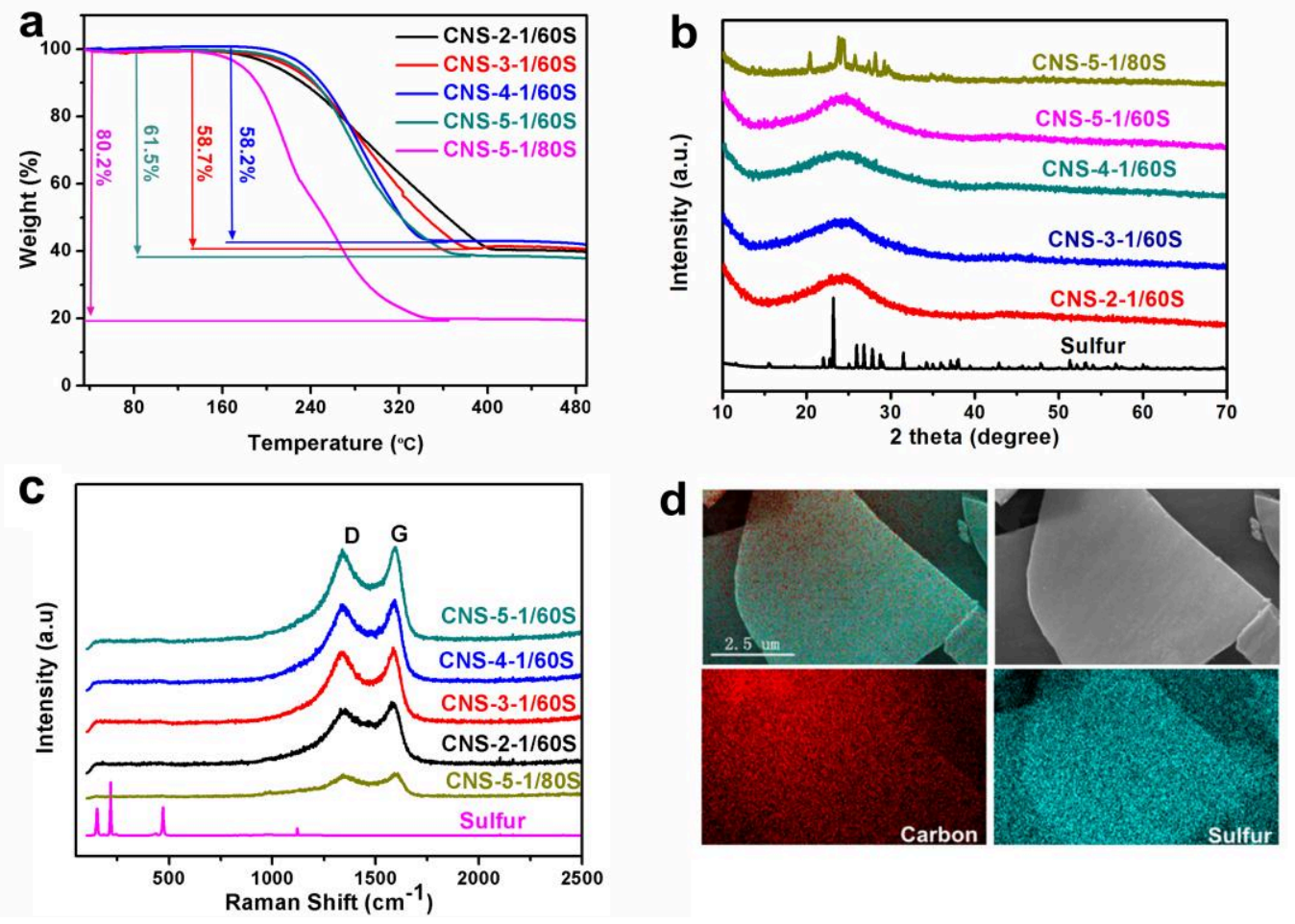

Figure 7. a) The TGA profiles forCNS-X-1/60S(X=2, 3, 4, 5) and CNS-5-1/80S. b) XRD patterns, c) Raman spectra for pristine sulfur, CNS-X-1/60S(X=2, 3, 4, 5) and CNS-5-1/80S. g) The elemental maps of CNS-5-1/60S. 

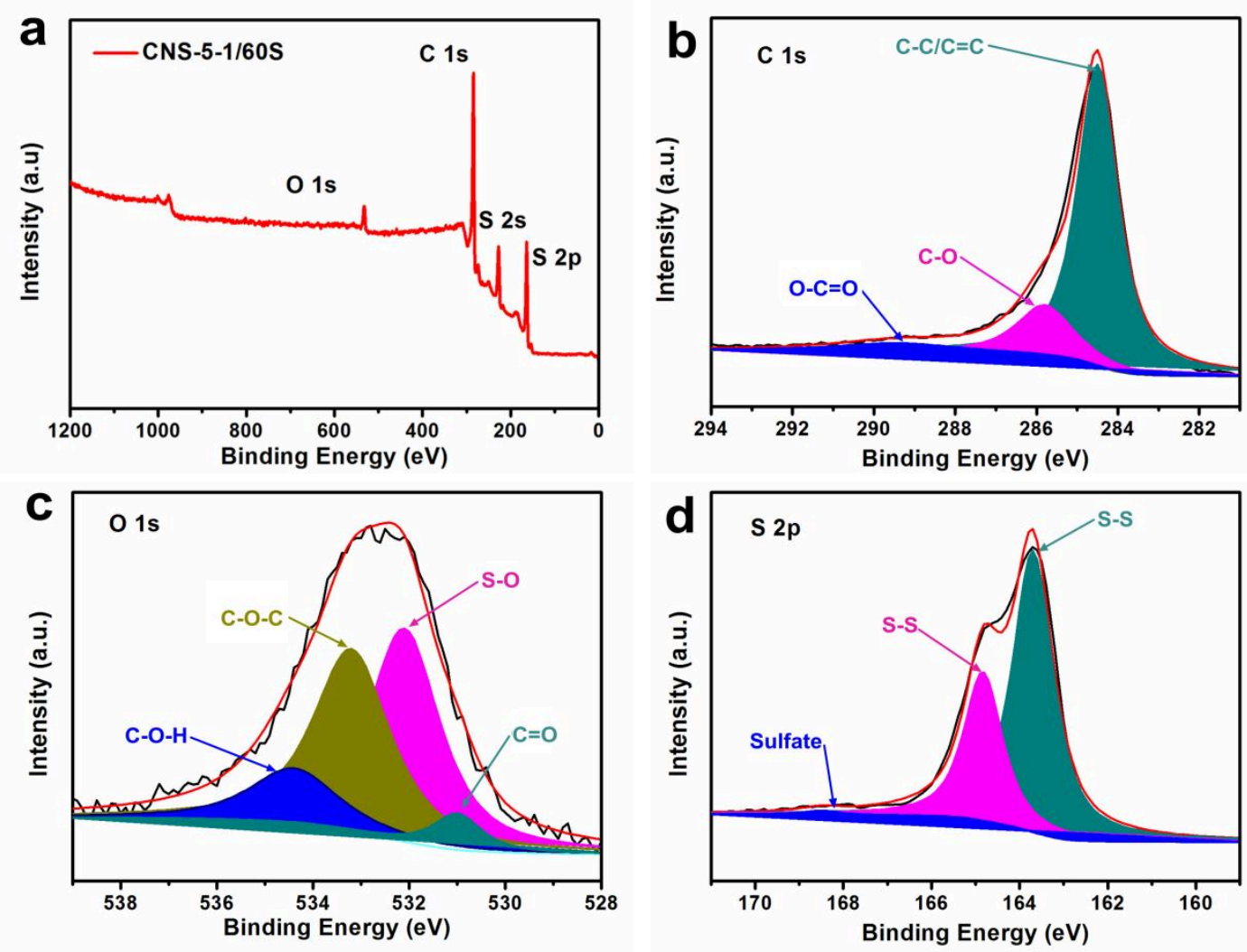

Figure 8. a) Overall XPS spectra of CNS-5-1/60S. b), c) and d) are matched XPS spectra of C 1s, $\mathrm{O} 1 \mathrm{~s}$ and $\mathrm{S} 2 \mathrm{p}$, respectively. 

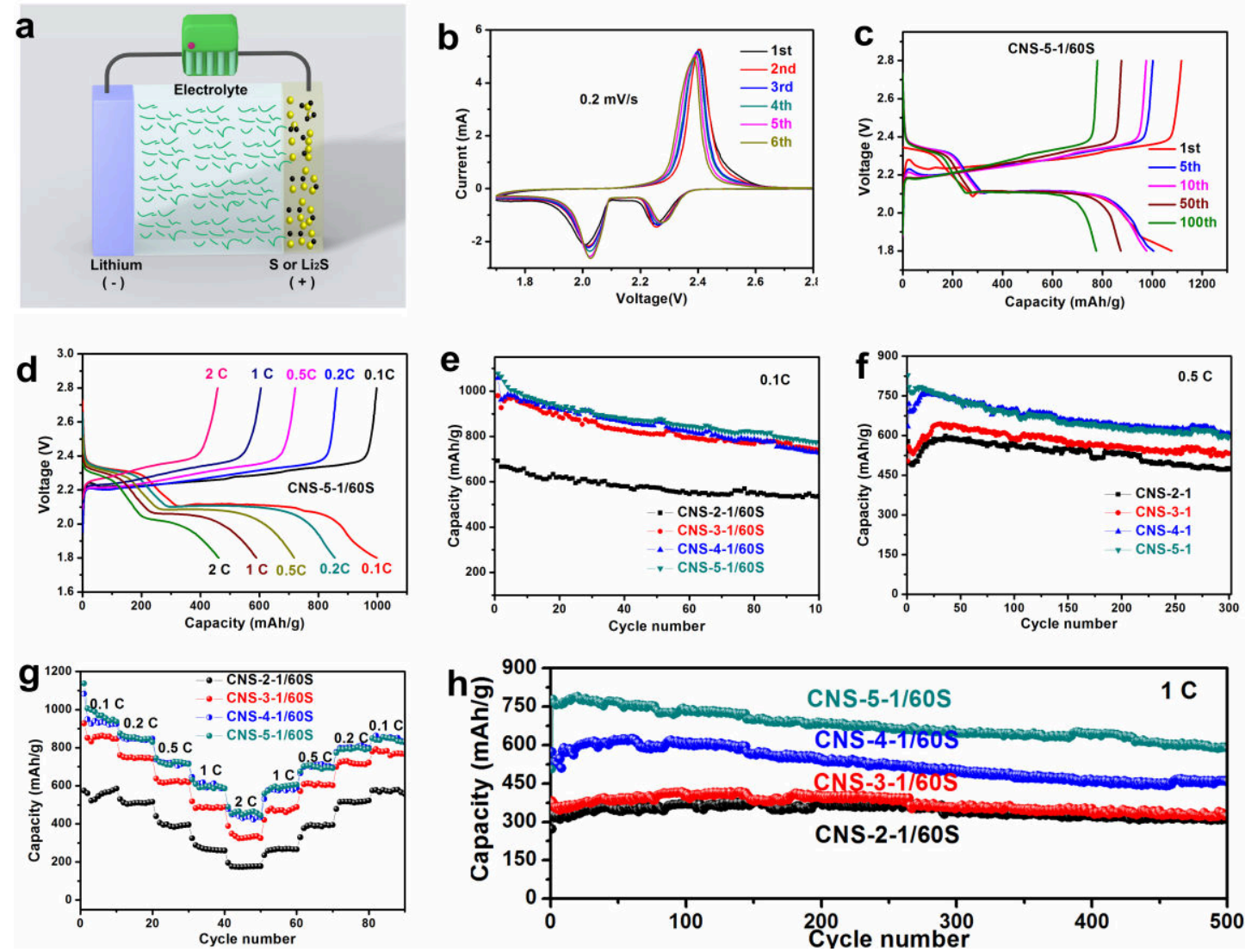

Figure 9. Electrochemical characterization of assembling lithium-sulfur batteries devices based on various CNS materials. a) Schematic illustration of the device configuration. b) CV curves of CNS-5-1/60S measured between 1.7 and $2.8 \mathrm{~V}$ versus $\mathrm{Li}^{+} / \mathrm{Li}$ at a sweep rate of $0.2 \mathrm{mV} \mathrm{s}^{-1}$. c) Charge-discharge profiles at a current density of $0.1 \mathrm{C}$ of CNS-5-1/60S cathode. d) Charge-discharge profiles at different rates of CNS-5-1/60S cathode. e) and f) are cycling performance curves of CNS-X-1/60S $(\mathrm{X}=2,3,4,5)$ electrodes at the current density of $0.1 \mathrm{C}$ and $0.5 \mathrm{C}$, respectively. g) The rate performance of CNS-X-1/60S(X=2, 3, 4, 5) electrodes. $h$ ) The long cycling performance of CNS-X-1/60S(X=2, 3, 4, 5) electrodes at the $1 \mathrm{C}$ rate. 

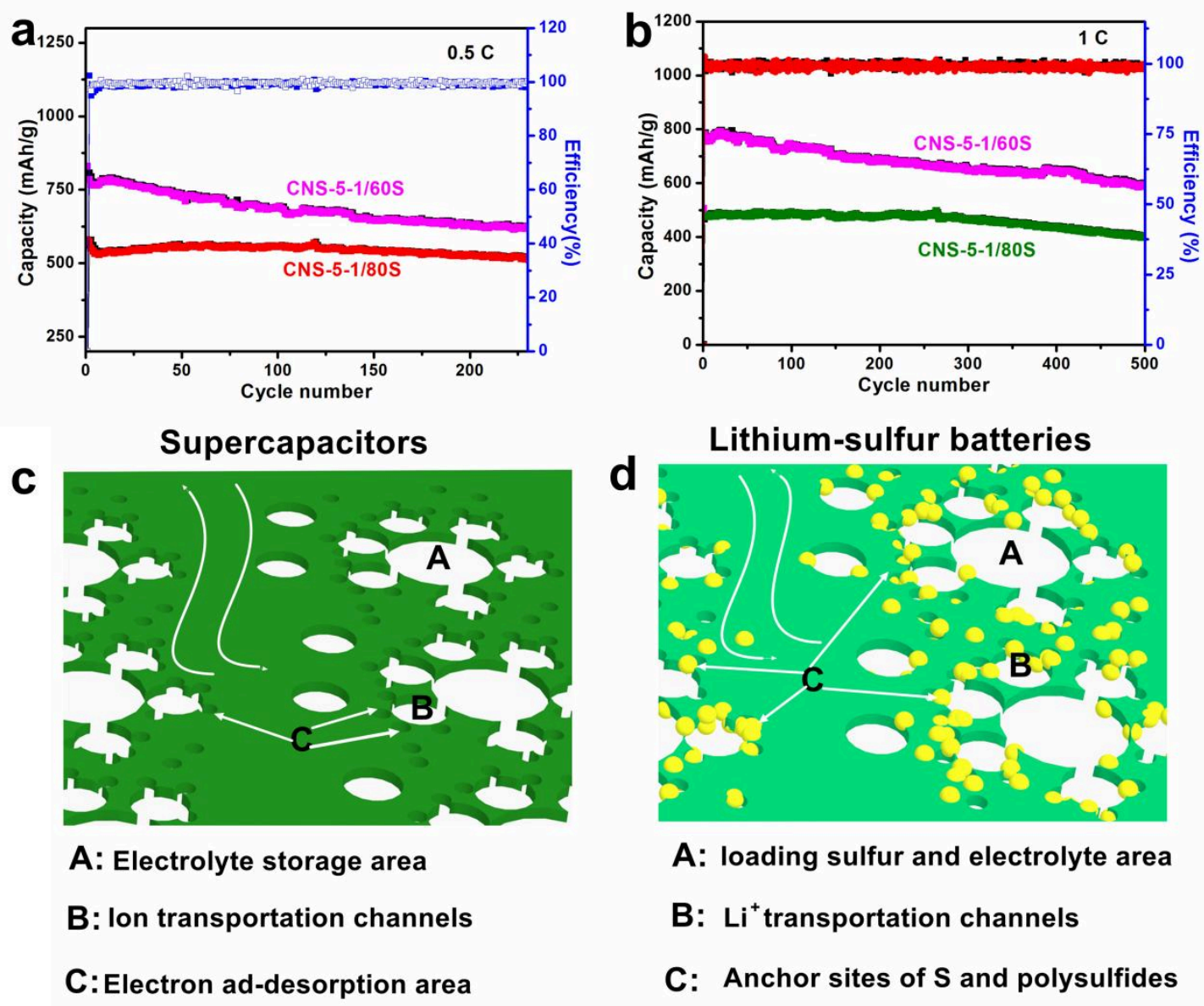

A: loading sulfur and electrolyte area

$\mathrm{B}: \mathrm{Li}^{+}$transportation channels

C: Anchor sites of $S$ and polysulfides

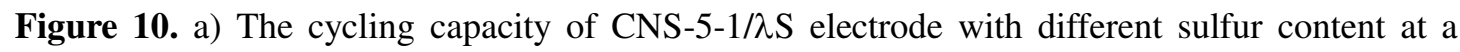
constant current density of $0.5 \mathrm{C}$. b) The cycling capacity of CNS-5-1 as electrode host materials at different sulfur content of 1 C. c) and d) The microstructure of CNS in SCs and lithium-sulfur batteries. 
Supplementary Material-video
Click here to download Supplementary Material: video-Supporting information.mp 4

Supplementary Material-video
Click here to download Supplementary Material: video-Supporting information.mp4 
Supplementary Material
Click here to download Supplementary Material: Supplementary material.docx

Supplementary Material
Click here to download Supplementary Material: Supplementary material.docx

$x$

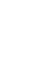

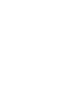

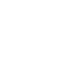

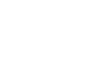

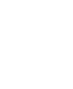

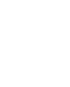

.

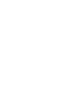

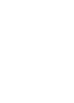

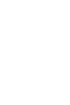

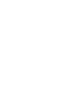

.

.

.

. 更

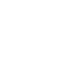

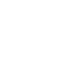

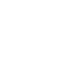
更

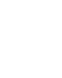

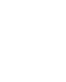

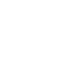

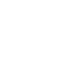

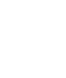

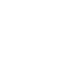
更

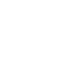

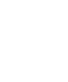

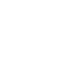

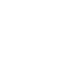


2019-09-10

\section{Facile synthesis of 2D ultrathin and} ultrahigh specific surface hierarchical porous carbon nanosheets for advanced energy storage

\section{Yao, Yuechao}

Elsevier

Yao Y, Xiao Z, Liu P, et al., (2019) Facile synthesis of 2D ultrathin and ultrahigh specific surface hierarchical porous carbon nanosheets for advanced energy storage. Carbon, Volume 155, December 2019, pp.674-685

https://doi.org/10.1016/j.carbon.2019.09.010

Downloaded from Cranfield Library Services E-Repository 